\title{
Single-point scratch testing for understanding particle engagement in abrasion of multiphase materials
}

\author{
Naveenkumar Rajendhran a, ${ }^{a}$, Patrick De Baets ${ }^{a}$, Shuigen Huang ${ }^{b}$, Jozef Vleugels ${ }^{b}$, Jacob Sukumaran ${ }^{a}$ \\ ${ }^{\text {a }}$ Soete Laboratory, Department of Electromechanical, Systems and Metal Engineering, Ghent University, B-9052 \\ Gent, Belgium \\ ${ }^{b}$ Department of Materials Engineering, Katholieke Universiteit Leuven (KU Leuven), B-3001 Leuven, Belgium
}

\section{Abstract}

The current research explores the influence of multi-asperity abrasive particles engagement on multiphase materials. WC-Co (WC- $15.6 \% \mathrm{Co}$ ) and NbC-cermet ( $\mathrm{NbC}-12 \% \mathrm{Ni}-10 \% \mathrm{Mo}_{2} \mathrm{C}$ ) hard materials were tested using a scale down single point scratch tester. Multi-asperity scratch patterns were produced by implying multiple scratches on hardmetal surface by parallel and repeated sliding. Superimposition of interactions has been implemented to study the damage evaluation of close-up parallel scratches. The abrasive particle characteristics such as size and apex angle were replicated by the diamond indenter and their influence with different applied loads [1-20 N] and sliding speeds [0.2 $-5 \mathrm{~mm} / \mathrm{s}$ ] were studied. NbC-cermet and WC-Co show a decrease in friction coefficient by $20-46 \%$ and $11-30 \%$ respectively, while the indenter tip radius changes from $200 \mu \mathrm{m}$ to $25 \mu \mathrm{m}$ under the same operating conditions. The wear micro-mechanism mainly changes from plastic deformation to fracture when the load and tip radius is increased. An extensive comparative study shows NbC-cermet prematurely experiences fracture dominated failure than its reference WC-Co. Moreover, tip size defect from indenter curvature geometry greatly affects the mean apex angle.

Keywords: Single point scratch test, multi-asperity abrasion, superimposition, multiphase materials

(1)

\footnotetext{
*corresponding author

Email - Naveenkumar.Rajendhran@UGent.be
} 


\section{Introduction}

Cemented carbides and cermets are a range of composites materials composed of hard carbide ceramic particles (WC, TiC, TaC and $\mathrm{NbC}$ ) bonded together by a metal binder ( $\mathrm{Ni}, \mathrm{Co}, \mathrm{Fe})$. These materials are widely used in tooling and wear parts applications because of the excellent properties such as hardness, toughness and wear resistance [1-3]. Wear due to abrasion is the leading cause of material failure in cutting tool applications where additional mechanisms such as oxidation, adhesion and diffusion wear during machining affect the lifetime of the tools $[4,5]$. The abrasion studies are divided into different modes/mechanisms based on the interaction between asperity (single and multiasperity) and dynamics of the abrasive particle (sliding and rolling) at interfaces [6, 7]. However, the interaction between the test materials and abrasive particles is an important element where material removal and the formation of residual deformation take place [8]. The wear mechanism is highly interchangeable due to the dynamics of the abrasive particle in the interface(s) [7]. The sliding of fixed particles or protuberances will scratch the surface of the test material. Multiple scratches can occur in contact with multiple asperities. On the other hand, rolling of the abrasive particle between the interfaces creates multiple indentations [6]. Combined sliding and rolling creates a mixture of scratches and indentations on surfaces. The input parameters such as material property and other operating conditions are the additional governing factor for modifying the wear micro-mechanism. However, the prevailing wear mechanisms are shown to be related to the movement of the active particle between the interface(s).

Much attention has been given to measuring the abrasion resistance and associated mechanism for surface damage of single and multi-phase materials on a laboratory scale [9-11]. Although the conventional abrasion tests such as dry/wet sand wheel abrasion and pin abrasion test are usually multi-asperity abrasion where the abrasion occurs through the simultaneous action of several abrasive particles [12]. Due to the irregular shape and dimensions of the abrasive particles, it is very complex to study the interactions between the surfaces and hard abrasive particles on a multi-asperity scale [8]. On contact with multiple asperities, the surface geometry produced by the grit particles is inconsistent each time [12]. This is due to the size distribution of the abrasive particles in the grit that experience different contact pressures due to the overall constant force covering the contact area. Therefore, the effective force carried by the interacting particle mainly depends on the abrasive particle size (distribution), shape and total abrasive concentration [6]. Literature suggests that studying the sliding interaction between the single abrasive particle and surface show a map of various wear mechanisms and associated surface damage [13]. Scratch testing is one of the major techniques that has been used for several years to evaluate the adhesive strength of the hard coatings [14]. Additional incorporation of acoustic emission makes this technique more useful for studying the coating failure which further can be used for damage assessment of the monolithic materials [15]. The fundamental interactions between the abrasive particles and surface can be easily mapped with the scratch test by a single point abrasive contact mode, where the indenter tip is used as an abrasive particle. The scratch test uses a single abrasive particle to simulate wear, allowing good control of particle movement [16].

Kayaba et al. performed an in-situ scratch test for ductile materials under scanning electron microscopy. The observations revealed that the scratch caused by the abrasive particles induces microscopically different wear patterns/modes called "wear micro-mechanisms". The wear micromechanisms such as micro-ploughing, wedge formation, flaking and cutting were differentiated based on the surface degree of penetrations [17]. The micro-ploughing mechanism represents the steadystate formation of a groove that has ridges on both sides formed by local plastic deformation without formation of wear debris. On the other hand, the continuous formation of curled microchips referred to a micro-cutting mechanism where ribbon-like wear debris is generated [17]. However, research on 
multiple asperities has suggested that the dynamics of abrasive particles is the main phenomenon for the prevailing wear mechanisms [18-20]. The effect of particle shape on particle movement has been reported by Fang et al. [19]. The report suggests that the rounded particles slide more and the angular particle more likely to roll between the interfaces but the movement of the patterns mainly depends on the spacing ration $(e / h)$. Mulhearn et al. showed the attack angle effect of the abrasive particle for determining the cutting mode transition of metals [21]. The wear transition from ploughing to cutting or debris formation occurs at a critical attack angle ( $30^{\circ}-90^{\circ}$ for most metals). However, the influence of size defects on the indenter curvature that lead to changes in the angle of attack has often been ignored due to smaller tip radius. Often, in metals this can be neglected due to the depth of the penetration provided by the indenter is larger than the size of the tip defect. On the other hand, ceramics and hardmetals provide very low surface penetration results. It is also noteworthy to mention that the above approach (single asperity testing and transition of wear modes) were often focused on metals and seldom on the cermets that will be studied in this research. Recently, Chicot et al. studied the influence of tip defect for different indenter shapes on the mechanical properties of the indentation system at a microscopic scale [22]. The defects in the curvature geometry of the indenter lead to the wrong estimation of the contact area, resulting in different hardness and elastic modulus values of nearly $10 \mathrm{GPa}$. Therefore, it is important to consider the indenter size and magnitude of the tip defect to obtain the precise wear results.

Research works on investigating the damage evaluation and prevailing wear mechanisms of multiphase cemented carbide (WC-Co) at single and multi-asperity abrasion contact were performed $[12,23,24]$. However, scarce report exists on linking the results between single and multiple asperities. The linking allows correlating the effect of engagement of abrasive particles against different operating conditions that can also be used for finding the transition in the wear mechanisms. Previously, Groenou et al. investigated the single point parallel scratches to understand the basic interaction between the abrasive particle and material surface in grinding and lapping process [8]. Mezlini et al. indicated the interaction between parallel scratches to perceive the transition in wear mechanisms of aluminium alloys [25]. Most recently, da silva et al. proposed a new methodology for demonstrating the movement of abrasive particles called "superimposition of interactions" to simulate a sequence of scratches and multiple indentations to achieve the movement of single abrasive particle interactions lead to abrasive wear contact. The proposed method reproduced the action of abrasive particles on the surface of the test material through a series of controlled interactions. This method also showed that the transition of wear mechanism from micro-ploughing to chip formation when the superimposition occurs for $\mathrm{M} 2$ tool steel [6]. The present study replicates the same methodology to simulate the similar scratch patterns produced by the sliding of close particles in multi-asperity abrasion by using single-point abrasive contact.

The current study focuses on linking the effect of abrasive particle engagements such as sliding and rolling, that cause different scratch and indentation patterns on contact with multi-phase materials, from the viewpoint of single asperity abrasion contact. The multi-asperity scratch patterns are produced by creating multiple scratches with respect to different contact kinematics such as parallel sliding, repeated sliding and rolling. Single pass and multi-pass scratches are used to reproduce the parallel and repeated contact sliding. Particle rolling is experimentally simulated by a contact fatigue mode using multiple indentations at a micro-scale. The superimposition effect was used to produced inconsistent scratch patterns using a series of well-controlled interactions. 


\section{Materials and methods}

\subsection{Materials}

The as-sintered $\mathrm{NbC}$-cermet ( $\mathrm{NbC}-12 \mathrm{Ni}-10 \mathrm{Mo}_{2} \mathrm{C}$, vol\%) and cemented carbide (WC-15.6 Co, vol\%) used in this study were provided by MTM KU-Leuven. The comprehensive material preparation and microstructure characteristics of these sintered carbides have been explained elsewhere [26]. The detailed chemical composition and mechanical properties are given in Table 1 . The density of the sintered cermets was measured in ethanol by the Archimedes method. The average grain size of the carbide grains was measured by the line intercept method using back-scattered electron images, without applying a correction factor. Vickers $\left(\mathrm{HV}_{30}\right)$ hardness was determined with a load of $294 \mathrm{~N}$ for $15 \mathrm{~s}$. Indentation fracture resistance, $\mathrm{K}_{\mathrm{IC}}$, was calculated according to the Shetty formula [27]. Five indentations on each material were made to obtain the mean and standard deviation. The room temperature flexural strength was measured in a three-point bending test (Instron 4467, PA, USA) on rectangular samples $(25 \times 3 \times 2 \mathrm{~mm}$ ) with a span length of $20 \mathrm{~mm}$ and a cross-head displacement of $0.1 \mathrm{~mm} / \mathrm{min}$. The reported mechanical properties are the mean and standard deviation of five tests. The test material was cylindrical with a diameter of $40 \mathrm{~mm}$ and a thickness of $5 \mathrm{~mm}$. A polishing procedure was carefully followed to achieve a mirror finish. The average initial surface roughness $\left(\mathrm{S}_{\mathrm{a}}\right)$ of the test sample was $0.02 \pm 0.01 \mu \mathrm{m}$, as suggested by the ASTM G171 standard [28].

Table 1. Properties

\begin{tabular}{|c|c|c|c|c|}
\hline Hardmetal & Composition & Properties & Value & Unit \\
\hline Cemented & WC-15.6 Co (vol\%) & Density & 14.765 & $\mathrm{~g} / \mathrm{cm}^{3}$ \\
\hline carbide & & Hardness $\left(\mathrm{HV}_{30}\right)$ & $1383 \pm 18$ & $\mathrm{~kg} / \mathrm{mm}^{2}$ \\
\hline \multirow[t]{5}{*}{ (WC-Co) } & & Toughness & $10.94 \pm 0.58$ & $\mathrm{MPa} \mathrm{m} \mathrm{m}^{1 / 2}$ \\
\hline & & E-modulus & 540 & $\mathrm{GPa}$ \\
\hline & & Flexural strength & $2900 \pm 100$ & $\mathrm{MPa}$ \\
\hline & & Poisson ratio & 0.31 & - \\
\hline & & Aver. grain size & 1.56 & $\mu \mathrm{m}$ \\
\hline \multirow[t]{7}{*}{ NbC-Cermet } & $\mathrm{NbC}-12 \mathrm{Ni}-10 \mathrm{Mo}_{2} \mathrm{C}$ & Density & 8.05 & $\mathrm{~g} / \mathrm{cm}^{3}$ \\
\hline & (vol\%) & Hardness $\left(\mathrm{HV}_{30}\right)$ & $1348 \pm 3$ & $\mathrm{~kg} / \mathrm{mm}^{2}$ \\
\hline & & Toughness & $8.29 \pm 0.1$ & $\mathrm{MPa} \mathrm{m} \mathrm{m}^{1 / 2}$ \\
\hline & & E-modulus & 440 & $\mathrm{GPa}$ \\
\hline & & Flexural strength & $1568 \pm 44$ & $\mathrm{MPa}$ \\
\hline & & Poisson ratio & 0.25 & - \\
\hline & & Aver. grain size & 2.14 & $\mu \mathrm{m}$ \\
\hline
\end{tabular}

\subsection{Microstructures}

The microstructure of the WC-Co and NbC-cermet was characterized through SEM-FEG (JEOL JSM7600F), see Fig. 1. The backscattered electron represents the dark interconnected structures are for the binder and bright contrast skeletons corresponding to the carbide phase. In Fig. 1b, the dark spots on $\mathrm{NbC}$ grains are indicating the residual porosity or $\mathrm{Nb}-\mathrm{O}$ oxide impurities during the sintering process. 

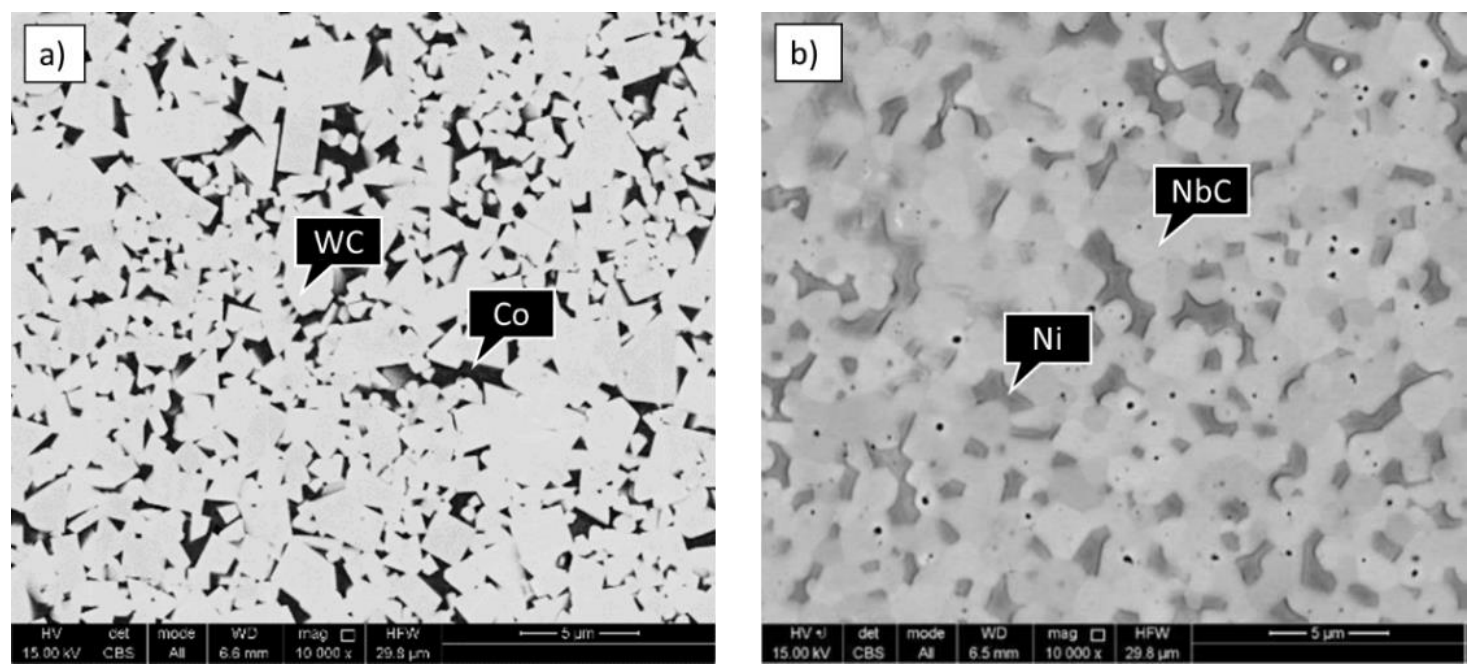

Fig. 1. SEM micrographs of multiphase (a) WC-Co and (b) NbC-cermet

\subsection{Methodology}

\subsubsection{Scratch tester}

A scratch test was performed by a universal mechanical tester (UMT tribolab), Bruker. The testing unit includes precision $\mathrm{X}$ and $\mathrm{Z}$ positioning $(1 \mu \mathrm{m}$ resolution) systems as well as various optional $\mathrm{Y}$ axial motion systems to control the location and loading force of the test specimen. The two dimensional (2D) force sensor ( $2.5 \mathrm{mN}$ resolution) are used to measure the sliding friction force between the indenter and test specimens as well as measuring and controlling the loading force. Further, the friction coefficient was measured from normal and frictional force results based on the ASTM D189414. An acoustic emission sensor ranging from 0.2 to $5.0 \mathrm{MHz}$ was connected with the indenter to detect the online damage evaluation. A UMT Lab view interface controls the movements of the samples and indenter. Fig. 2 shows the configuration of the UMT scratch tester.

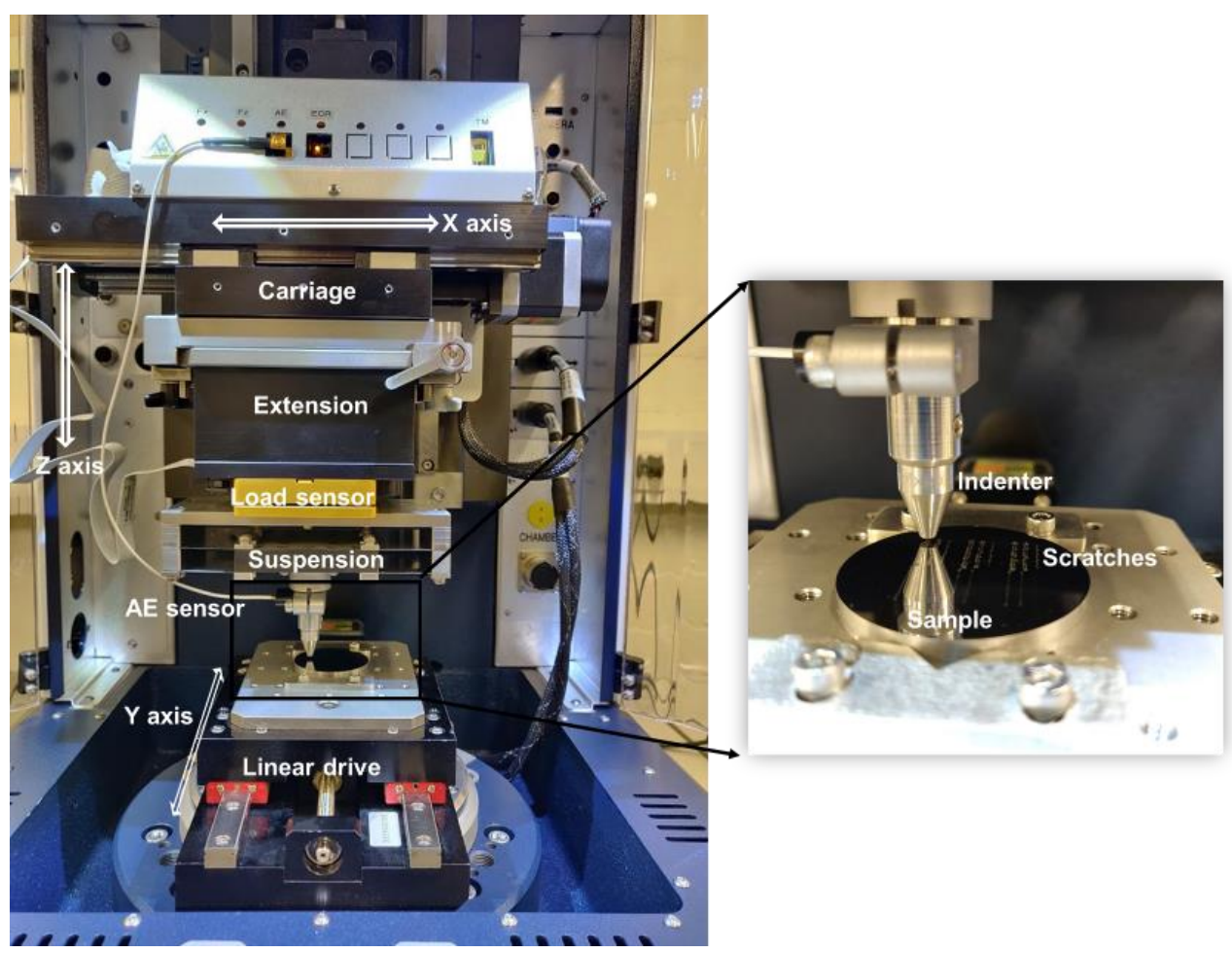

Fig. 2. UMT scratch tester 


\subsubsection{Relationship between load and penetration parameters}

To establish the relationship between applied normal load and penetration parameters such as depth and width, tests have been conducted with individual indentation and scratch with different loads, as shown in Fig. 3. The tests were performed through a standard Rockwell indenter $\left(200 \mu \mathrm{m}, 120^{\circ}\right)$ and the scratch speed of the system kept constant at $0.2 \mathrm{~mm} / \mathrm{s}$. The results show that the penetration depth indicates a linear relationship with the applied load. The depth produced by the scratch is relatively less than the indentation depth. On the other hand, it can be seen that the average scratch width is relatively equivalent to the indentation width when the load is up to $40 \mathrm{~N}$, then the trend behaves differently. Using these experimental results, the effect of load and scratch width was deduced and the degree of superimposition was performed.
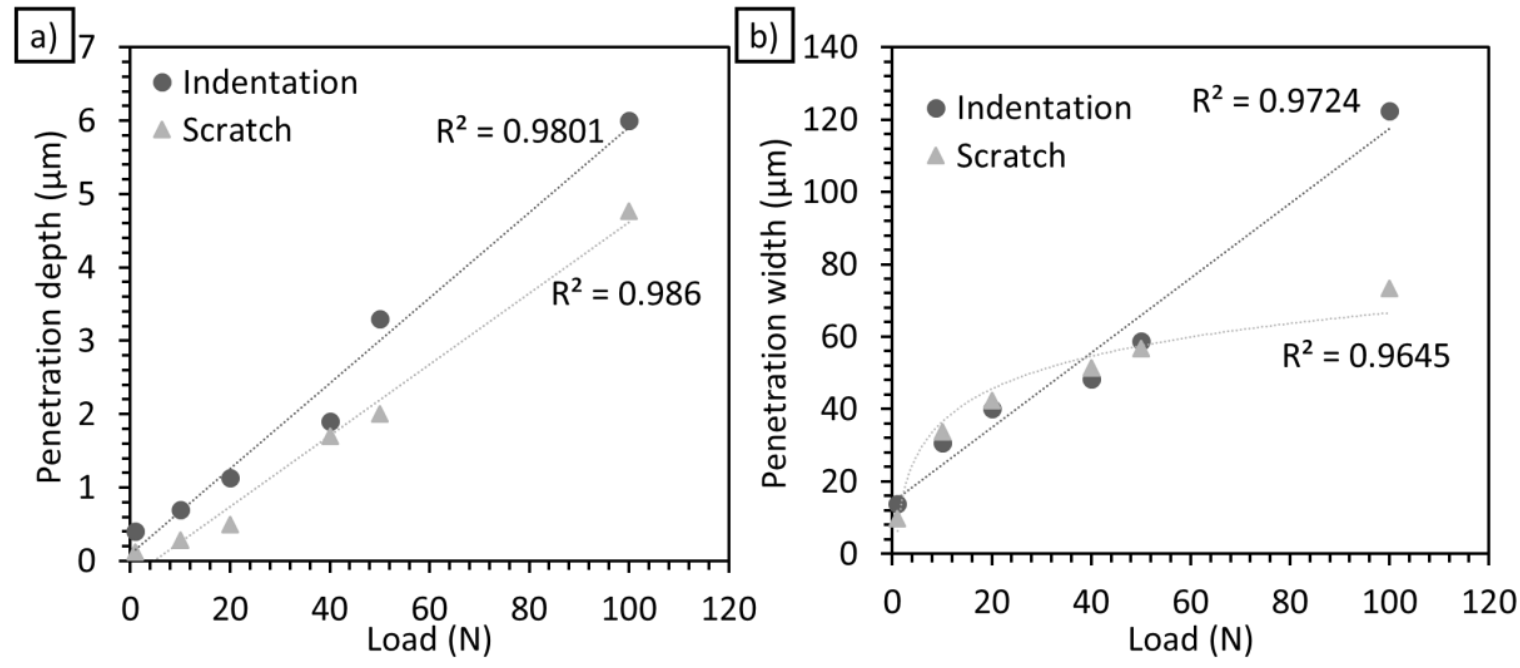

Fig. 3. Effect of load on the (a) penetration depth and (b) width

\subsubsection{Evaluation of the size deviation of the indenter tip}

Literature suggests that the size defect of the indenter highly influence the variation of the contact area [22]. The size deviation or size of the tip defect of the indenter refers to the distance between the ideal indenter point (where the apex angle starts) and the rounded indenter point in service. Fig. 4 shows the tip of the conical indenter for an average apex angle of $120^{\circ}$ with different tip radius namely (a) $200 \mu \mathrm{m}$ (b) $100 \mu \mathrm{m}$ (c) $50 \mu \mathrm{m}$ (d) $25 \mu \mathrm{m}$. The size deviation of the tip corresponds to the length between the ideal edge of the indenter and the round indenter tip in use. A detailed size deviation of different apex angle with respect to the tip radius of the indenters are shown in Fig. 5 . The trend clearly shows that the size deviation increases as the tip radius $(25-200 \mu \mathrm{m})$ of the indenter increases. On the other hand, increasing apex angle results in large deviation in the size. However, during scratching the $25 \mu \mathrm{m}$ with $60^{\circ}$ apex angle indenter considerably failed at $10 \mathrm{~N}$ load for both material cases. This is because the contact resistance provided by the surface of the material is certainly higher than the compressive stress of the diamond indenter. 

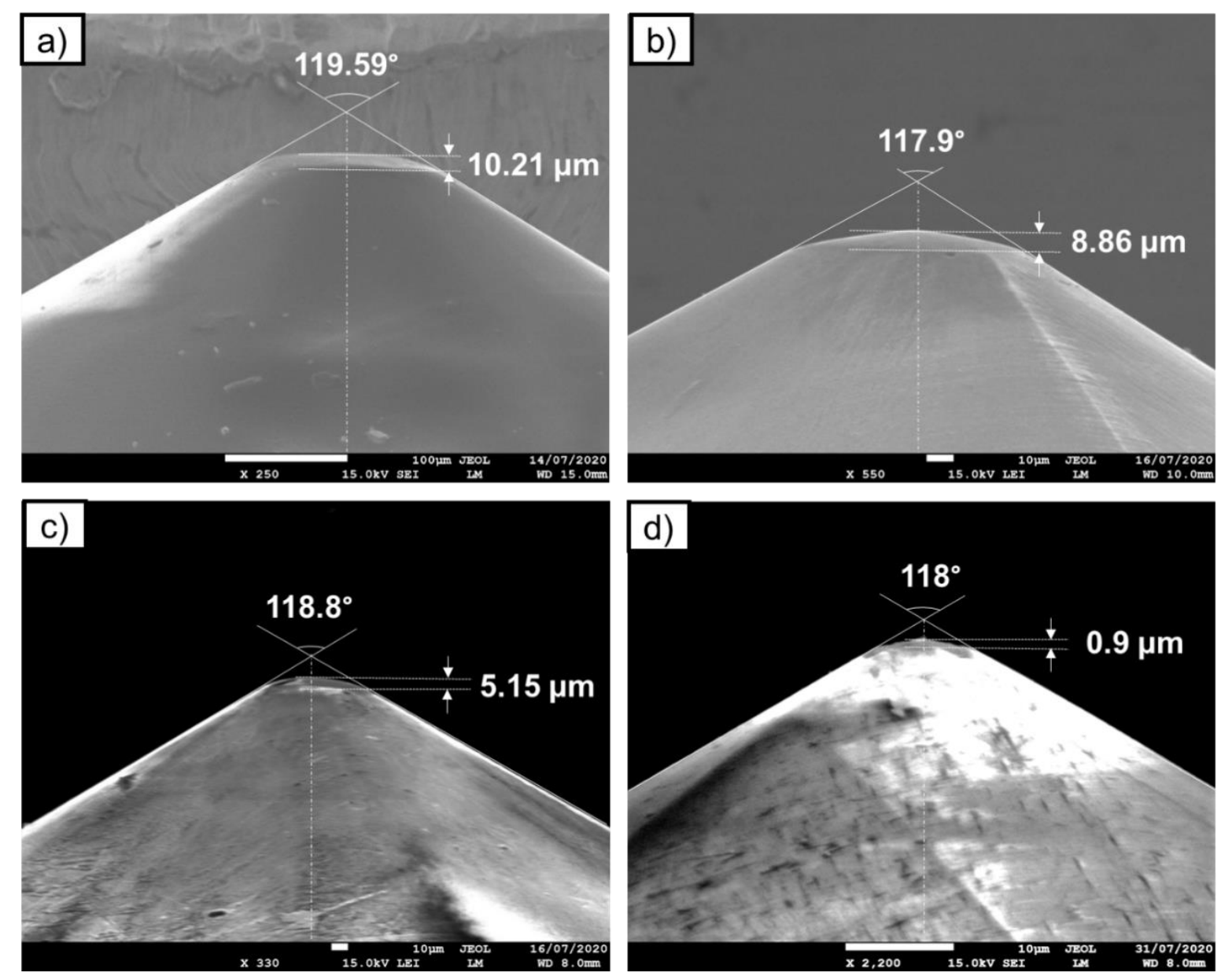

Fig. 4. Indenter size defect evaluation for a tip radius of (a) $200 \mu \mathrm{m}$ (b) $100 \mu \mathrm{m}$ (c) $50 \mu \mathrm{m}$ (d) $25 \mu \mathrm{m}$

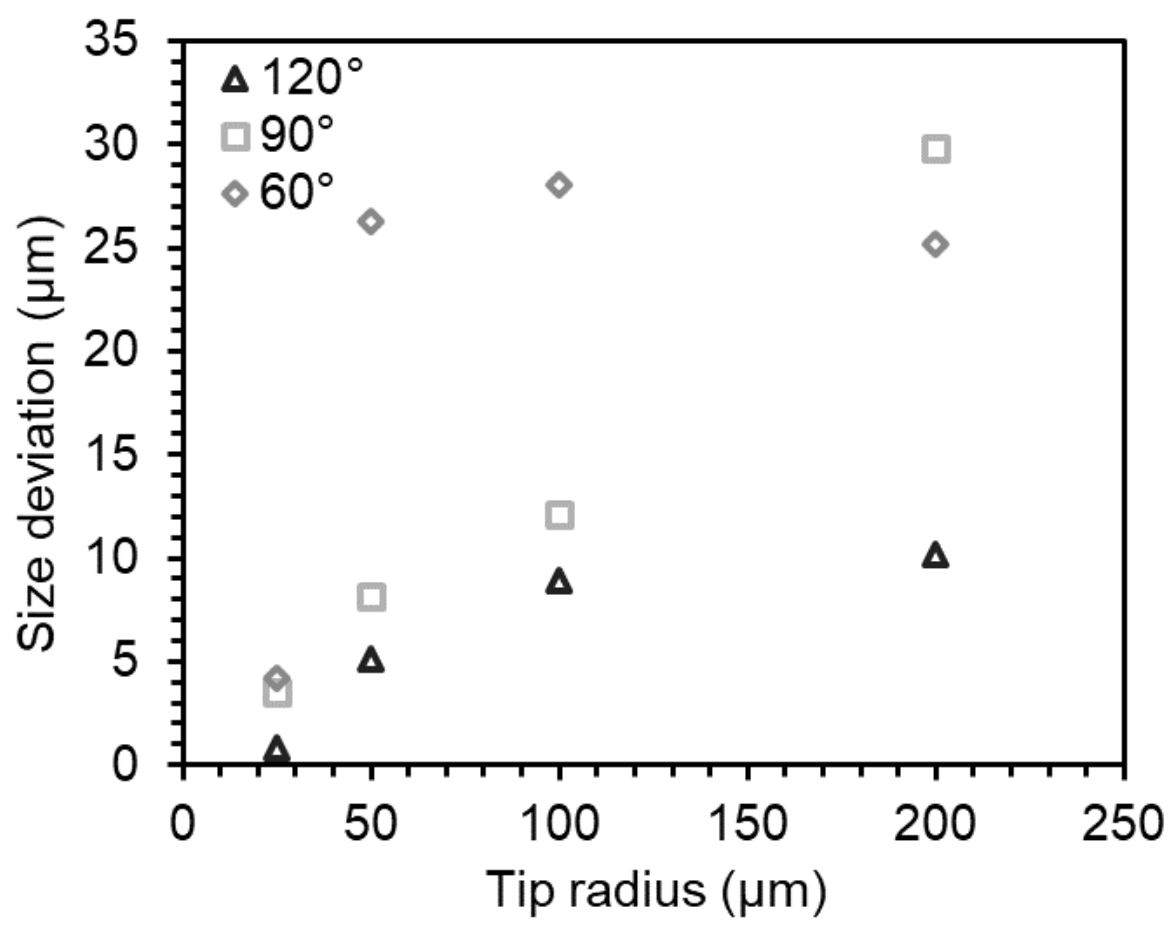

Fig. 5.Tip radius vs. size deviation 


\subsubsection{Single, multi-pass scratch testing and indentation characterization}

The single point parallel scratches were simulated by moving a polished sample under a vertically loaded diamond indenter. A conical diamond indenter with four different tip radius ranging from 25 $200 \mu \mathrm{m}$ and three different apex angle $2 \theta=60^{\circ}, 90^{\circ}$ and $120^{\circ}$ were used to simulate the scratches of different abrasive contacts. The test load was primarily chosen constantly between $1 \mathrm{~N}$ to $20 \mathrm{~N}$ to achieve the scratch length of $10 \mathrm{~mm}$. The sliding speed was chosen between $0.2-5 \mathrm{~mm} / \mathrm{s}$ as suggested from the standards [28]. For the multi-pass repeated scratch mode, an array of 3 scratches $(10,50,100$ passes) separated at $2 \mathrm{~mm}$ distance were performed on the sample with constant load ranging from 1 $\mathrm{N}$ to $20 \mathrm{~N}$. The repeated scratches were achieved by multiple passes on the same wear track followed by reciprocating mechanisms. The test speed of the system was kept low at $0.2 \mathrm{~mm} / \mathrm{s}$ for both loads to avoid the frictional heating between the sample surface and counterface. The detailed test conditions are summarized in Table 2.

Table 2. Test conditions for single pass and multi-pass scratch test

\begin{tabular}{ccccccc}
\hline $\begin{array}{c}\text { Type of } \\
\text { the } \\
\text { scratch }\end{array}$ & Load $[\mathrm{N}]$ & $\begin{array}{c}\text { Sliding speed } \\
{[\mathrm{mm} / \mathrm{s}]}\end{array}$ & Distance & $\begin{array}{c}\text { Tip radius } \\
{[\mu \mathrm{m}]}\end{array}$ & $\begin{array}{c}\text { Apex angle } \\
{\left[{ }^{\circ}\right]}\end{array}$ & $\begin{array}{c}\text { Direction of } \\
\text { sliding }\end{array}$ \\
\hline $\begin{array}{c}\text { Single } \\
\text { pass }\end{array}$ & $\begin{array}{c}1-20[1,5, \\
10,20]\end{array}$ & $\begin{array}{c}0.2-5[0.2, \\
1,2.5,5]\end{array}$ & $\begin{array}{c}10 \mathrm{~mm} \\
\text { length }\end{array}$ & $\begin{array}{c}25-200 \\
{[25,50,} \\
100,200]\end{array}$ & $120,90,60$ & Single \\
\hline $\begin{array}{c}\text { Multi- } \\
\text { pass }\end{array}$ & $\begin{array}{c}1-20[1,5, \\
10,20]\end{array}$ & 0.2 & $\begin{array}{c}10,50,100 \\
\text { passes } \\
10 \mathrm{~mm} \\
\text { length }\end{array}$ & 200 & 120 & Reciprocating \\
\hline
\end{tabular}

The superimposition effect of indentation was studied by performing a sequence of indentation lines. The test was carried out by standard Rockwell conical indenter with a tip radius of $200 \mu \mathrm{m}$ and an apex angle of $120^{\circ}$. Two different normal loads namely $1 \mathrm{~N}$ and $20 \mathrm{~N}$ were used to study the load effect. The maximum length of the indentation lines was set as $400 \mu \mathrm{m}$. The number of indentations gradually increased by decreasing the distance between the indentations to study the variation of the superimposition effect, see Fig. $\mathbf{6}$. Table $\mathbf{3}$ summarizes the test conditions to simulate the lines of indentations. The degree of superimposition (DoS) was calculated from the distance between the indentations (DI) and width of the indentations (WI) according to Eq. (1) [6].

$$
\operatorname{DoS}=\frac{\mathrm{WI}-\mathrm{DI}}{\mathrm{WI}} \times 100 \%
$$




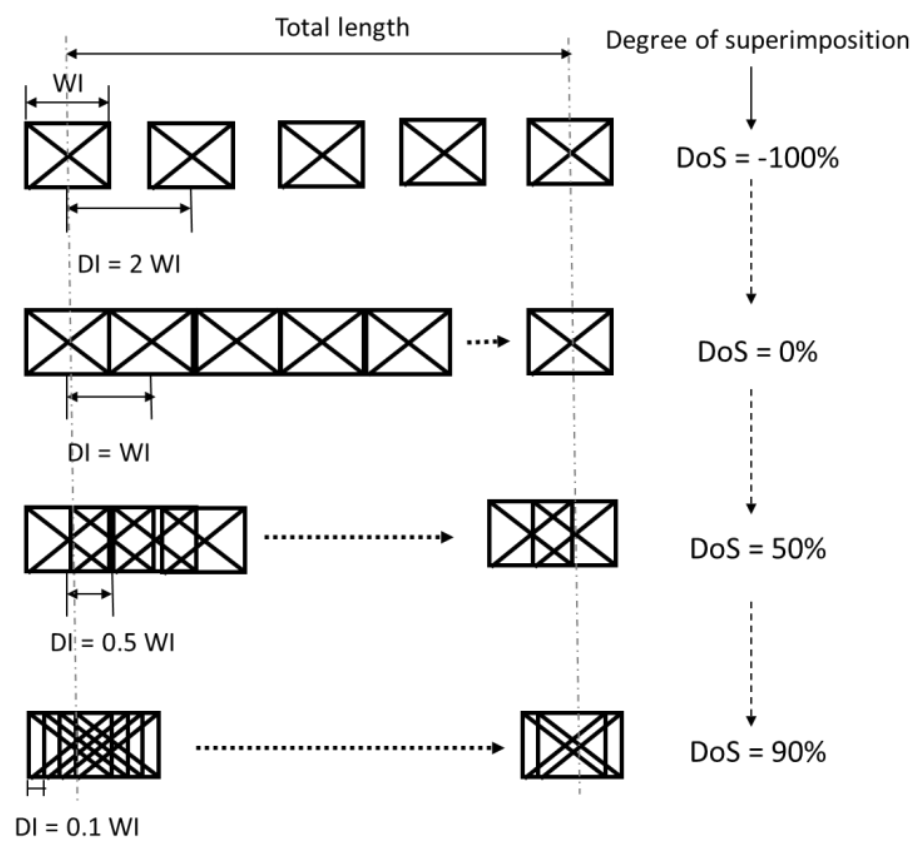

Fig. 6. Schematic representation of superimpositions of interactions [6]

3 Table 3. Test conditions for superimposition of indentations

\begin{tabular}{|c|c|c|c|c|c|c|c|c|c|}
\hline \multirow{2}{*}{$\begin{array}{l}\text { Load } \\
\text { (N) }\end{array}$} & \multirow{2}{*}{$\begin{array}{c}\text { Contact } \\
\text { width } \\
(\mu \mathrm{m})\end{array}$} & & \multicolumn{7}{|c|}{ Degree of superimposition (\%) } \\
\hline & & & -100 & -50 & -25 & 0 & 25 & 50 & 90 \\
\hline \multirow[b]{2}{*}{1} & \multirow[b]{2}{*}{15} & $\mathrm{DI}(\mu \mathrm{m})$ & 30 & 22.5 & 18.75 & 15 & 11.25 & 7.5 & 1.5 \\
\hline & & $\begin{array}{c}\text { No. of } \\
\text { indentations }\end{array}$ & 14 & 18 & 22 & 28 & 36 & 54 & 267 \\
\hline \multirow[b]{2}{*}{20} & \multirow[b]{2}{*}{40} & $\mathrm{DI}(\mu \mathrm{m})$ & 80 & 60 & 50 & 40 & 30 & 20 & 4 \\
\hline & & $\begin{array}{c}\text { No. of } \\
\text { indentations }\end{array}$ & 5 & 7 & 8 & 10 & 14 & 20 & 100 \\
\hline
\end{tabular}

For parallel scratches, the degree of superimposition was established at low $(1 \mathrm{~N})$ and high load (20 N) to study the load effect. The standard Rockwell indenter with $200 \mu \mathrm{m}$ tip radius and $120^{\circ}$ apex angle was performed in this test. The test was performed by a fixed sliding speed of $0.2 \mathrm{~mm} / \mathrm{s}$ for a sliding distance of $5 \mathrm{~mm}$. The parallel scratches were simulated with different scratch distance (SD) for a maximum width of $100 \mu \mathrm{m}$. Table 4 shows the test condition to simulate the parallel scratch with different degree of superimposition. The width of the scratch (WS) was taken from the preliminary studies for both low and high load and the degree of superimposition calculated according to Eq. (2).

$$
\mathrm{DoS}=\frac{\mathrm{WS}-\mathrm{SD}}{\mathrm{WS}} \times 100 \%
$$

Table 4. Test conditions for the superimposition of scratches

\begin{tabular}{ccccccccccc}
\hline \multirow{2}{*}{$\begin{array}{c}\text { Load } \\
(\mathrm{N})\end{array}$} & $\begin{array}{c}\text { Sliding } \\
\text { speed } \\
(\mathrm{mm} / \mathrm{s})\end{array}$ & $\begin{array}{c}\text { Contact } \\
\text { width } \\
(\mu \mathrm{m})\end{array}$ & & \multicolumn{6}{c}{ Degree of superimposition (\%) } \\
\cline { 4 - 10 } & & \multirow{2}{*}{15} & SD $(\mu \mathrm{m})$ & 30 & -50 & -25 & 0 & 25 & 50 & 90 \\
\hline \multirow{2}{*}{1} & \multirow{2}{*}{0.2} & & No. of scratches & 4 & 5 & 6 & 7 & 9 & 14 & 67 \\
& & & SD $(\mu \mathrm{m})$ & 80 & 60 & 50 & 40 & 30 & 20 & 4 \\
20 & & 40 & No. of scratches & 2 & 2 & 2 & 3 & 4 & 5 & 25 \\
\hline
\end{tabular}


After each test, the defect of the indenter was monitored and cleaned by ethanol before it was used for the next test. Ambient parameters such as temperature and relative humidity $(\mathrm{RH})$ recorded during the testing ranged between $23^{\circ} \mathrm{C}-28^{\circ} \mathrm{C}$ and $48 \%-57 \%$, respectively. After testing, the samples were thoroughly cleaned by ethanol to remove the loose debris particle on the surface for further morphology and topography characterizations. Each scratch test was repeated three times to check repeatability and the average was reported in the results.

\subsection{Worn surface characterization}

Worn surface characteristics such as morphology and topography are the key parameters to identify the wear mechanism. The morphology of worn surfaces were characterised through scanning electron microscopy (SEM) coupled with energy dispersive X-ray (EDS) from JEOL JSM-7600F. A Taylor Hobson $\mathrm{CCl}-\mathrm{HD}$ white light interferometer was used to analyse the surface topography of the indentation and scratched surface. The extracted topographic data was further analysed through Talysurf $\mathrm{CCl}$ software to find the cross-section scratch areas, depth and width of the profile (see Fig. 7). The wear volume (V) was further calculated based on the Archard according to the relationship Eq. (3) [29].

$$
V=V_{g}-V_{r}=l\left(A_{g}-A_{r}\right)
$$

Where the volume parameters $V_{g}$ and $V_{r}$ are calculated from the area of the groove $\left(A_{g}\right)$ and ridges $\left(A_{r}\right.$ $\left.=A_{r 1}+A_{r 2}\right)$ and $l$ is the scratch distance. The average surface groove and ridge areas (due to ridge formation and material build-up) are highlighted with a red and green spot.

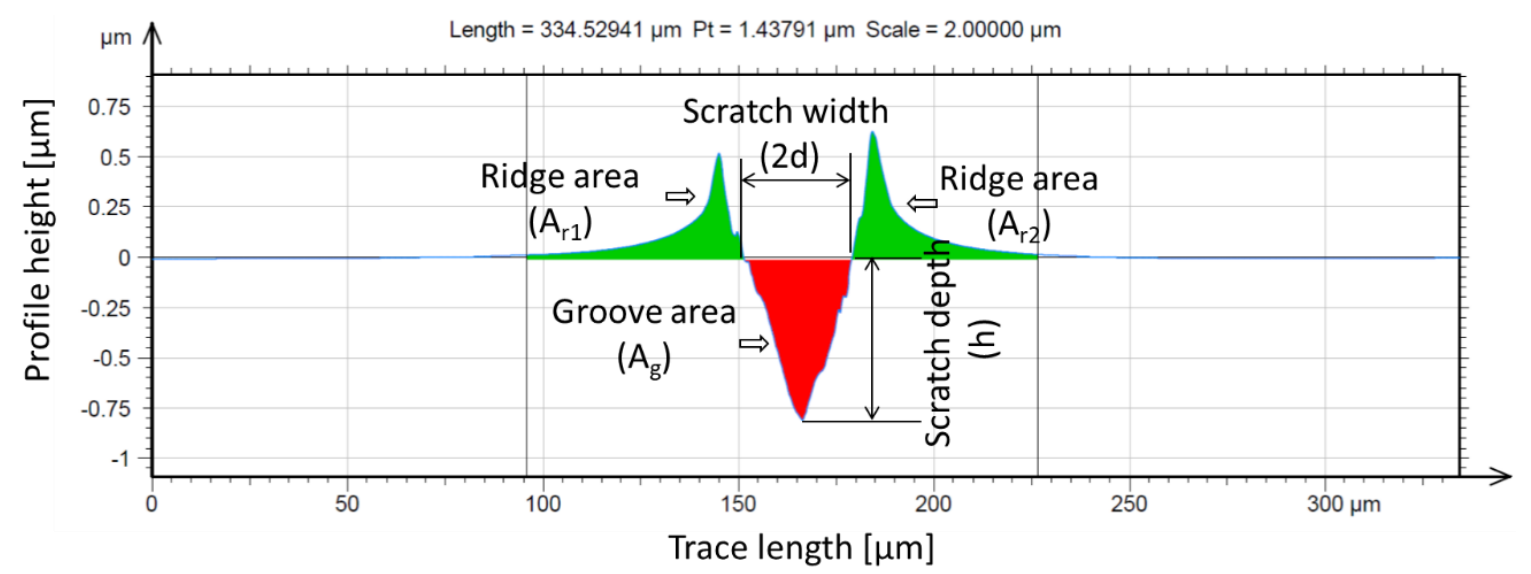

Fig. 7. Cross section view extracted from the scratch profile 
The effect of operational parameters such as load and sliding speed on single pass scratch was studied in detail. The test results show the friction coefficient of two different tip radius namely $200 \mu \mathrm{m}$ (Fig. $\mathbf{8 a}$ ) and $25 \mu \mathrm{m}$ (Fig. 8b) indenters with an approximate apex angle of $120^{\circ}$. The mean friction coefficient of both WC-Co and NbC-cermet shows a rapid increase between the loads ( $1 \mathrm{~N}$ to $5 \mathrm{~N}$ ) and then the trend increased gradually. Despite the same load and speed, the mean friction coefficient for NbCcermet tested with $200 \mu \mathrm{m}$ indenter shows a decrease of 20-46\% (approx.) compared to WC-Co. On the other hand, the rate of changes in the friction coefficient for NbC-cermet with $25 \mu \mathrm{m}$ indenter shows $11-30 \%$ (approx.) decrease compared to WC-Co. The friction coefficient showed a decreasing trend when the system speed increased for both $200 \mu \mathrm{m}$ and $25 \mu \mathrm{m}$ indenters. The statistics show no significant variation and accepts the null hypothesis at this stage.
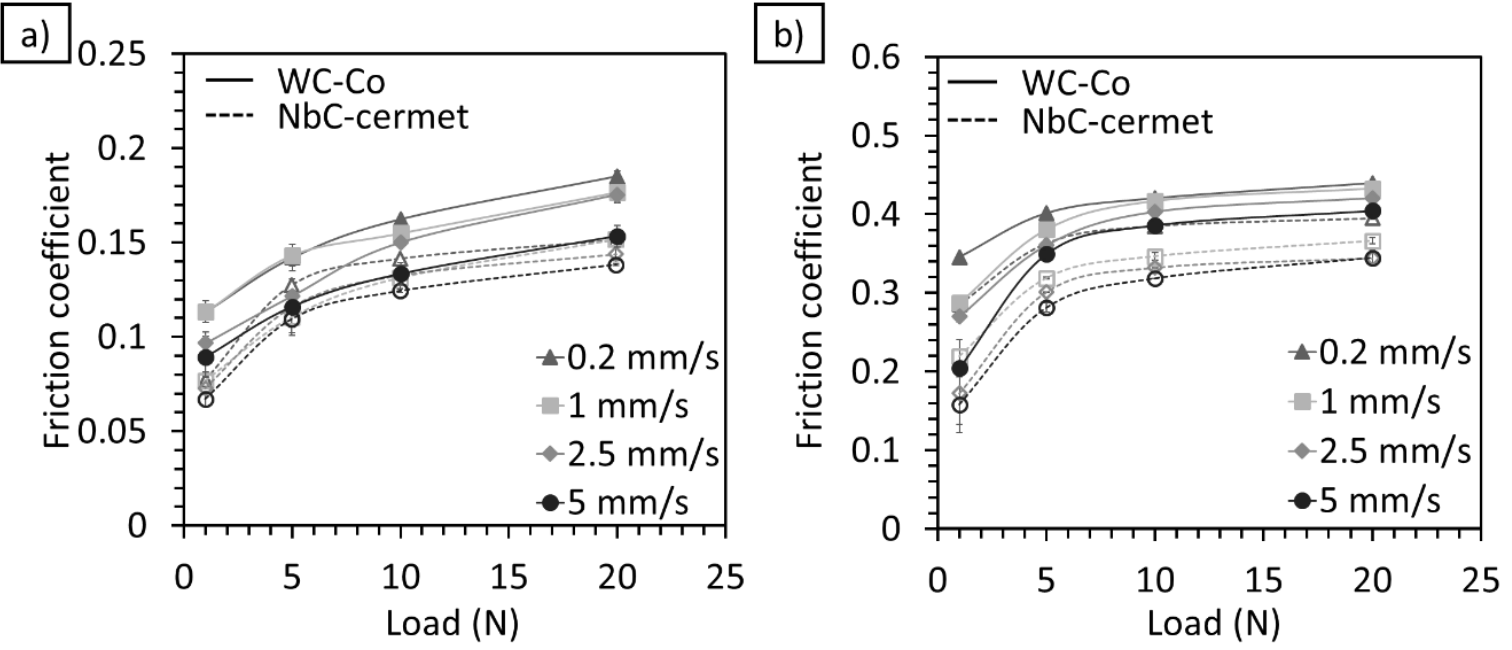

Fig. 8. Effect of load and speed on friction coefficient for (a) $200 \mu \mathrm{m}$ and (b) $25 \mu \mathrm{m}$ indenter

Wear in terms of scratch width and depth are the possible means to measure the damage assessment. In most cases, the scratch width measures to control the wear, while the depth or volume loss is more important for the wear resistance application. Fig. 9a-b emphasizes the increasing load that results in greater scratch depth and width on both surfaces for $200 \mu \mathrm{m}$ indenter. However, NbC-cermet offers a low scratch depth (about 74-87\%) than WC-Co under the same operating conditions. When the load is low, WC-Co offers a smaller scratch width but the trend has changed significantly to a high scratch width when the system load is high. On the other hand, NbC-cermet provides an identical logarithmic increase in the scratch width. At $20 \mathrm{~N}$ load, both materials offer an approximately equal amount of scratch width. The variation in scratch depth and width, relative to the sliding speed indicates that no clear trend was observed for both NbC-cermet and WC-Co. The scratch results of $25 \mu \mathrm{m}$ indenter support the above explanation of the effect of loading, but no significant variations in scratch depth and width were observed (Fig. 9c-d). An indenter with $25 \mu \mathrm{m}$ tip radius exhibits an order of magnitude higher scratch width than that of the $200 \mu \mathrm{m}$ tip radius. Noticeably, the overall scratch depth and width show a decreasing trend as the sliding speed increases for $25 \mu \mathrm{m}$ indenter. 

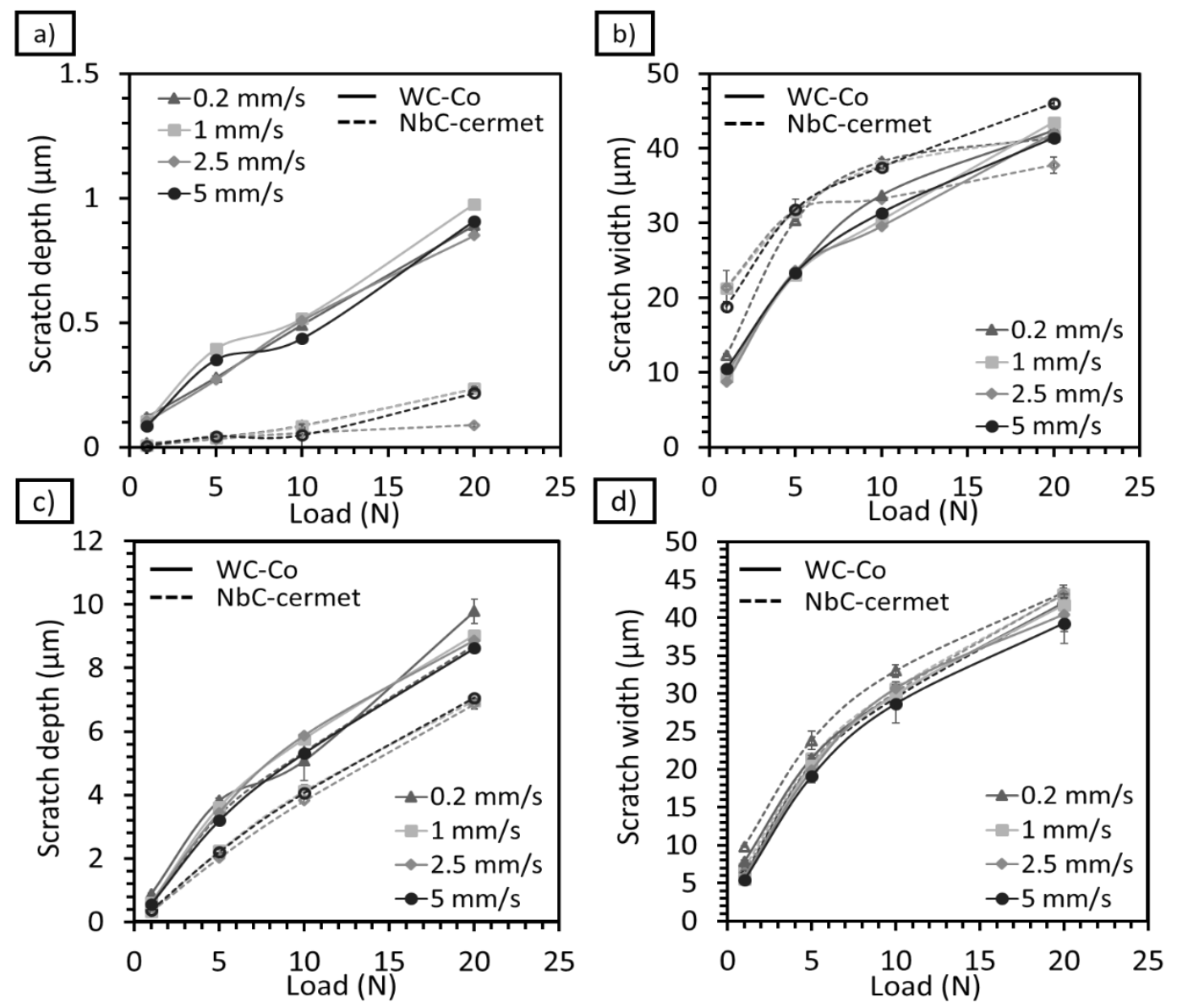

Fig. 9. Effect of load and speed on scratch depth and scratch width for (a,b) $200 \mu \mathrm{m}$ and (c,d) $25 \mu \mathrm{m}$ indenter

Wear in terms of volume loss of both NbC-cermet and WC-Co for $200 \mu \mathrm{m}$ and $25 \mu \mathrm{m}$ indenter is shown in Fig. 10. It is noted that the volume loss of WC-Co exhibits an order of magnitude higher than NbCcermet for a $200 \mu \mathrm{m}$ indenter with the same test conditions (Fig. 10a). However, the results show an equal trend varied when the penetration size was reduced to $25 \mu \mathrm{m}$ indenter (Fig. 10b). It is quite clear that the wear volume increases when the system load increases, but there is no clear trend in the sliding speed for either test case.
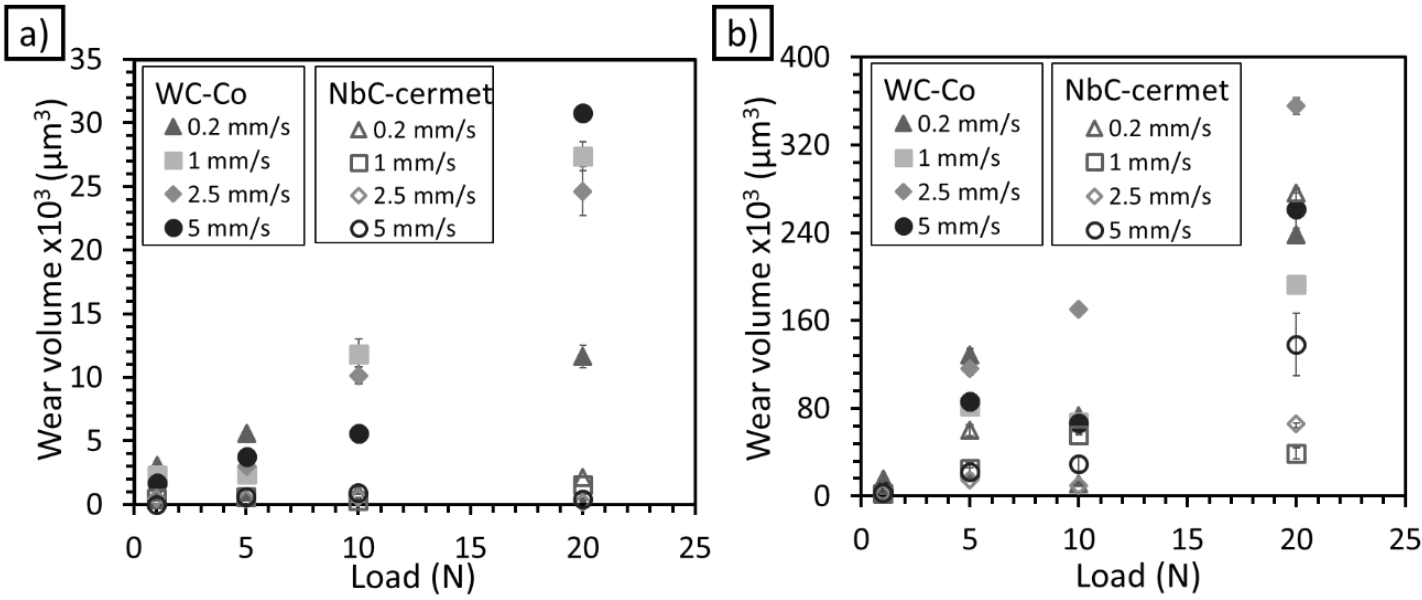

Fig. 10. Wear volume loss of NbC-cermet and WC-Co with respect to load and speed for (a) $200 \mu \mathrm{m}$ and (b) $25 \mu \mathrm{m}$ indenter 


\subsubsection{Effect of tip radius}

The effect of indenter tip radius on the scratch performance was showed in Fig. 11. The test condition was performed at a sliding speed of $0.2 \mathrm{~mm} / \mathrm{s}$ with different indenter tip radius ranging from $25 \mu \mathrm{m}$ to $200 \mu \mathrm{m}$ with an apex angle of $120^{\circ}$. The rate of friction coefficient was decreased significantly when the tip radius of the indenter increased $(25 \mu \mathrm{m}$ to $200 \mu \mathrm{m}$ ). In both material cases, the friction provided by the $25 \mu \mathrm{m}$ indenter shows three times greater than that of the $200 \mu \mathrm{m}$ indenter. Additionally, the low friction coefficient attests for NbC-cermet compared to WC-Co and the effect is more pronounced between the indenter size $25 \mu \mathrm{m}$ to $100 \mu \mathrm{m}$ (Fig. 11a). The variation in the scratch depth shows a clear decreasing trend when the tip radius increased from $25 \mu \mathrm{m}$ to $200 \mu \mathrm{m}$ (Fig. 11b). However, there was no clear trend in the scratch width. In particular, a $50 \mu \mathrm{m}$ indenter indicates a lower scratch depth for both NbC-cermet and WC-Co (Fig. 11c). The wear volume shows a decreasing trend with the penetration size but there is no clear trend in the load variation (Fig. 11d). Besides, NbC-cermet shows a higher volume loss than WC-Co when the indenter size is small $(25 \mu \mathrm{m})$.
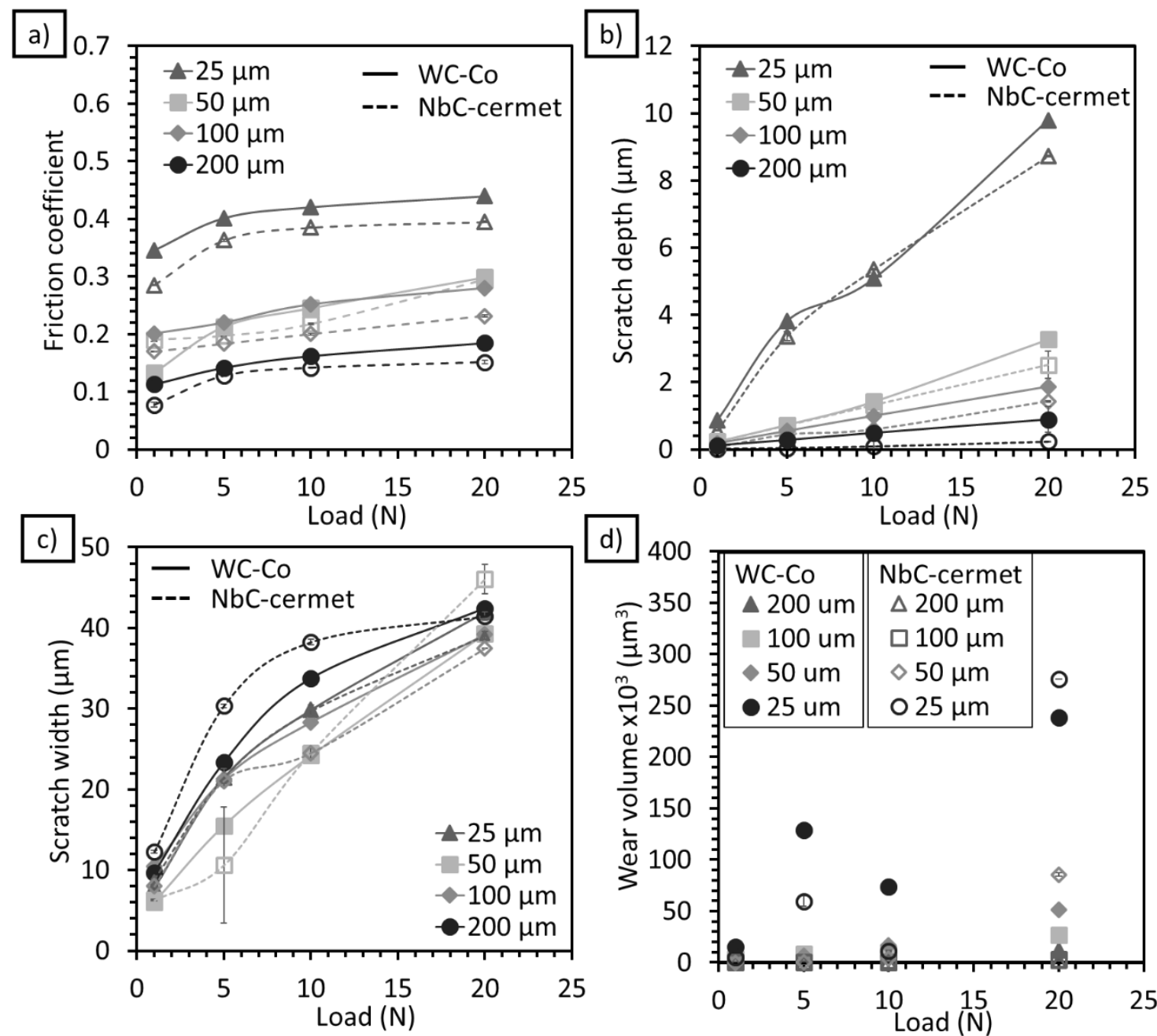

d)

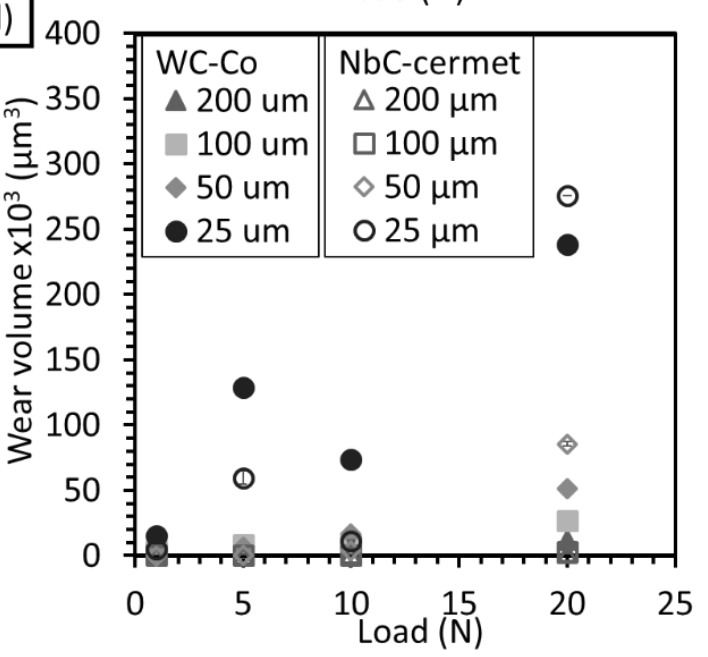

Fig. 11. Effect of load and tip radius on (a) friction coefficient (b) scratch depth (c) scratch width and (d) wear volume

\subsubsection{Effect of an apex angle}

The apex angle is another important parameter to study the influence attack angle of the abrasive particles during scratching. This can be studied by varying the apex angle of the indenter from $60^{\circ}$ to $120^{\circ}$ with a sliding speed of $0.2 \mathrm{~mm} / \mathrm{s}$. Fig. 12 shows the effect of an apex angle for NbC-cermet and 
WC-Co with respect to the load. It can be noticed that the scratch depth of the materials decreased when the apex angle of the indenter increases. There was no appropriate trend in the scratch width of the WC-Co, but NbC-shows an increasing scratch width as the apex angle increases. The volume loss of both WC-Co and NbC-cermet for different apex angles shows different results and no clear trend was observed (Fig. 12c).

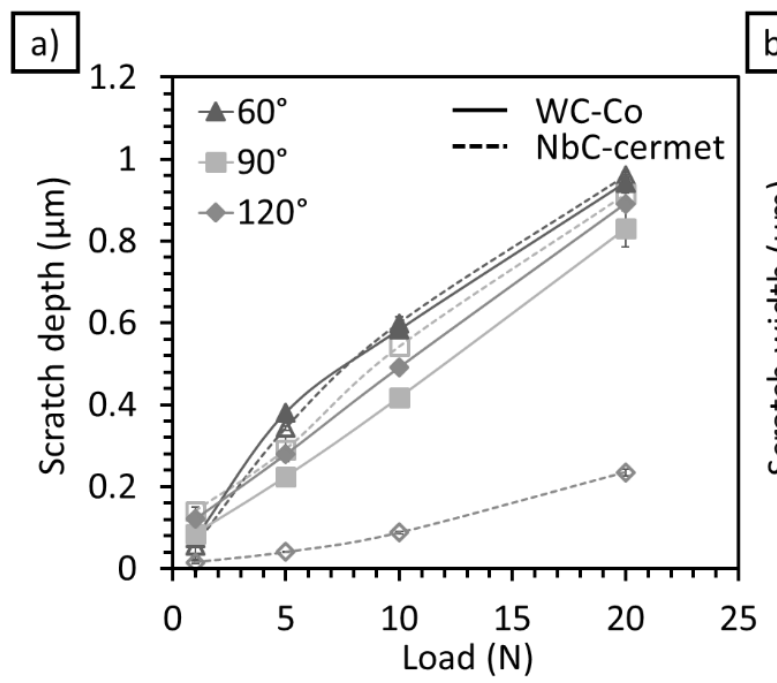

b) 60
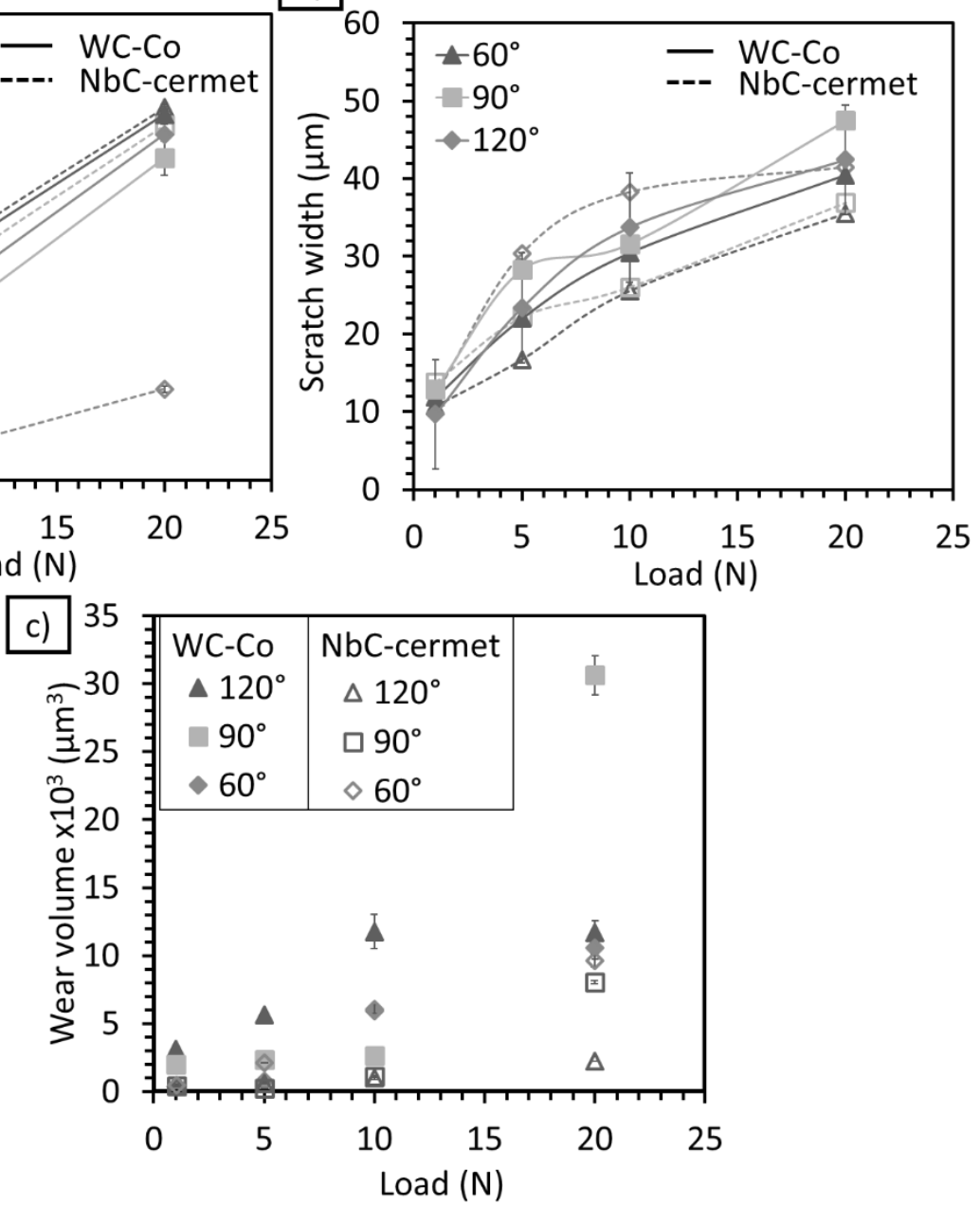

Fig. 12. Effect of load and apex angle on (a) scratch depth (b) scratch width (c) wear volume

\subsubsection{Effect of indenter size deviation in the scratch results}

As mentioned earlier in the experimental section, the deviation in the size of the indenter was closely related to the radius of the tip. In most test cases, the curvature of the tip (based on tip radius) has not been fully covered within the penetration depth. Therefore the resulting attack angle is relatively different from the mean attack angle. Schematic illustration clearly shows the size effect in the surface penetration of the indenter against hard material and ceramics (Fig. 13a). The influence of the angle of attack certainly occurs where the penetration depth reaches $h$, but in this case the penetration reaches only half of the curvature referred as $h_{1}$. The comparison between the obtained scratch depth and the size deviation of the indenter with different apex angles at higher load is shown in Fig. 13b. The results clearly show that the value of the $h$ fully penetrated on the surface only for $25 \mu \mathrm{m}$ indenter, here the angle of attack has been encountered in the damage process. For the rest of the tip radius $(50-200 \mu \mathrm{m})$, the angle of attack depends mainly on the curvature effect. Thus, the observed similarity in the scratch results for different apex angles is simply due to the size deviation of the indenter. 

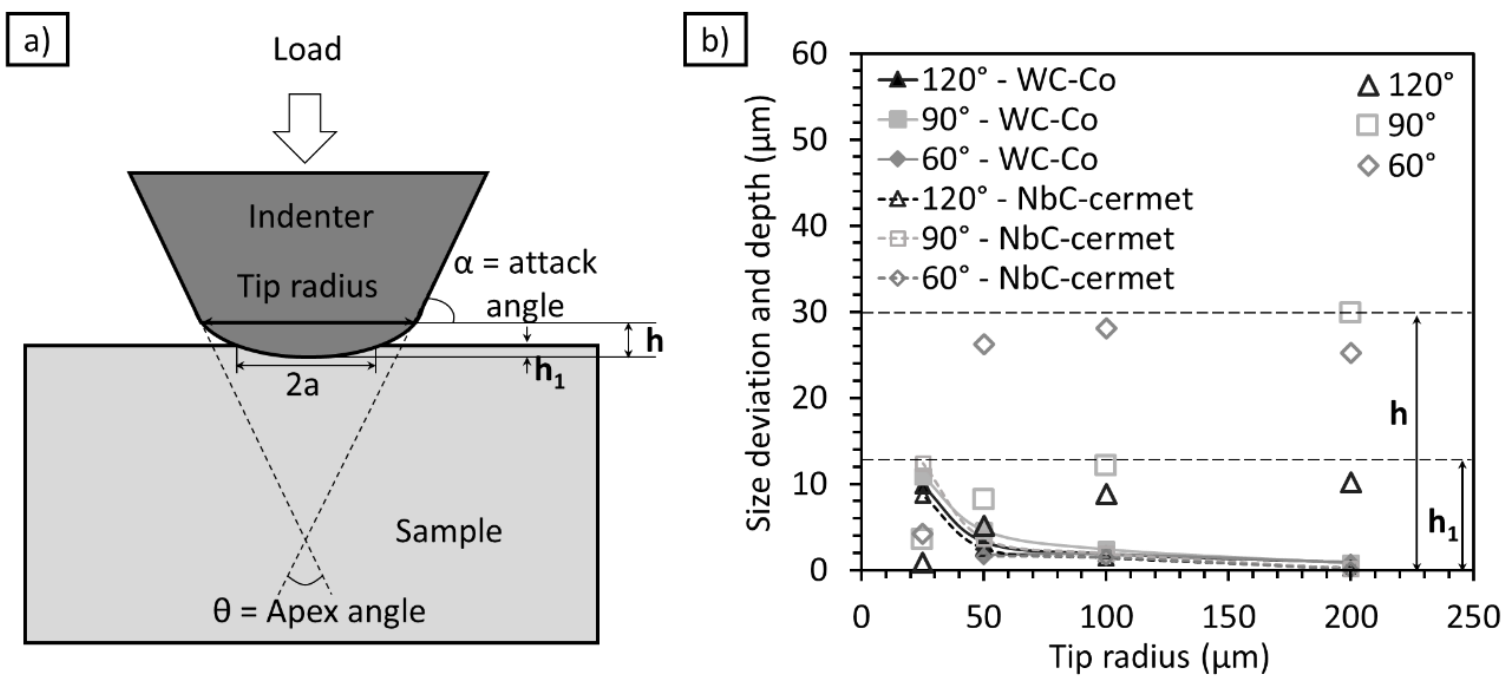

1

Fig. 13. (a) Schematics of indenter engagement on the surface of multiphase materials (b) effect of indenter size defect on scratch depth for different apex angle vs. tip radius

\subsection{Multi-pass repeated scratches}

The key purpose of performing the repeated scratches is to find the accumulation of damage during multiple passes performed in the same location of the sample. The detailed friction results with respect to the number of passes for WC-Co and NbC-cermet was clearly illustrated in Fig. 14a\&b. The results show that there are two main observations in the friction coefficient when the number of passes and system load increases. In the case of WC-Co, there is a significant increase in the value of the friction coefficient during 1-10 passes then the trend increased gradually. On the other hand, NbC-cermet shows a decreasing trend between passes 1-10 and it behaved independently. Noticeably, $1 \mathrm{~N}$ load performs different behaviour in the friction results for $\mathrm{NbC}$-cermet cases compared to the other loads $(5-20 \mathrm{~N})$.
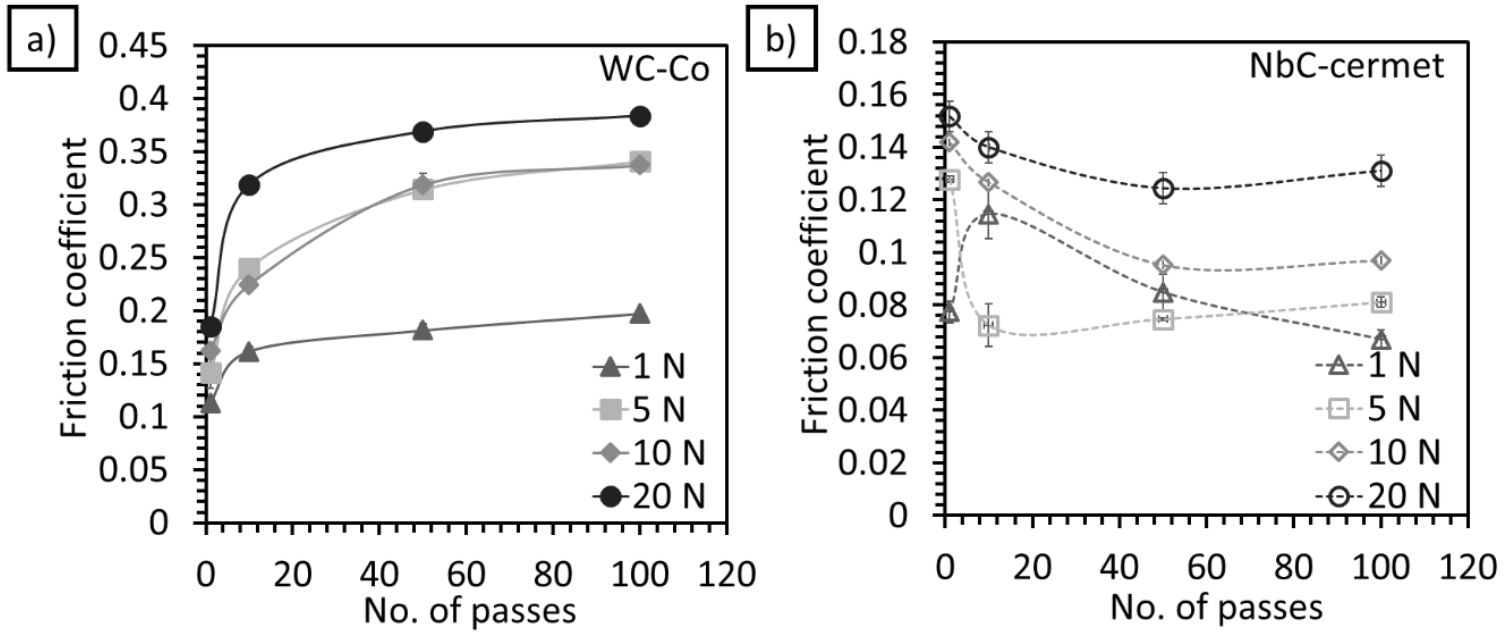

Fig. 14. Friction coefficient of (a) WC-Co and (b) NbC-cermet vs. number of passes

The depth and width of the scratches for NbC-cermet show an order of magnitude lower than the WCCo (Fig. 15a-b). The increasing load shows an upward trend for both NbC-cermet and WC-Co. Thus, it became clear that increasing the load initiates the high material removal from the surfaces during multi-pass experiments. Further, It is noticeable that both depth and width increase between passes 1-10 then the trend becomes a steady state for the NbC cermet. On the other hand, WC-Co shows an 
upward trend when the number of passes increases. Comparatively, the amount of material removal is significantly low in the case of NbC-cermet as compared to WC-Co. The volume loss of both WC-Co shows a marked upward trend in the logarithmic scale as the number of passes increases (Fig. 15c). $\mathrm{NbC}$-cermet on the other hand shows a very low wear volume than the WC-Co (Fig. 15d).

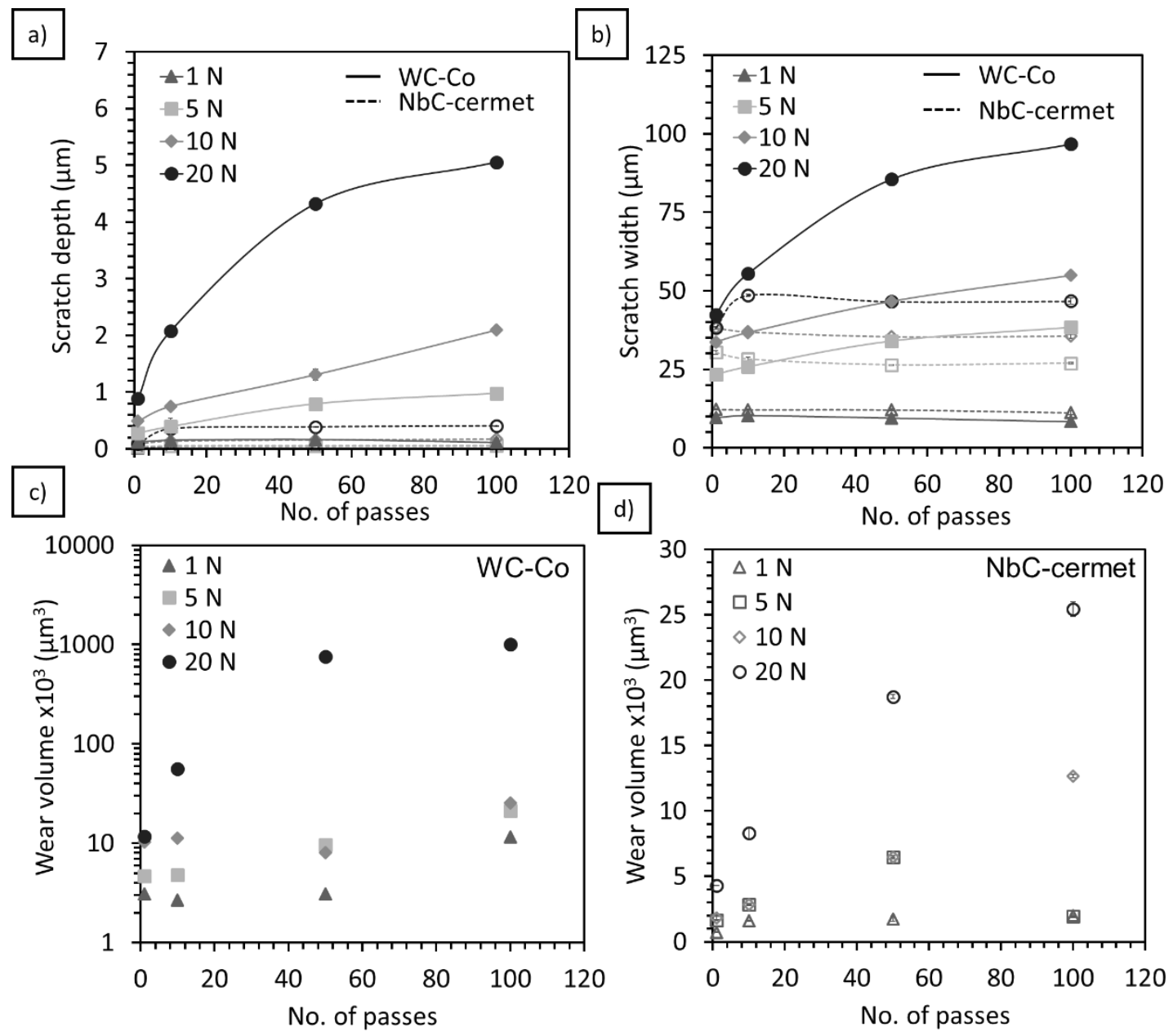

Fig. 15. Number of passes vs. (a) scratch depth (b) scratch width (c) wear volume of WC-Co and (d) wear volume of $\mathrm{NbC}$-cermet

\subsection{Surface examination}

\subsubsection{Single pass}

Fig. 16a-d shows the SEM micrograph of the WC-Co against $200 \mu \mathrm{m}$ indenter at various loads (1-20 N) with a fixed sliding speed of $0.2 \mathrm{~mm} / \mathrm{s}$. At low load $(1 \mathrm{~N})$, the multiphase WC-Co shows a sign of plastic deformation observed by traces of slip lines (arrow highlighted) and some evidence of binder extrusion and WC granular cracks (Fig. 16a). When the system load increases to $5 \mathrm{~N}$, it can lead to severe plastic deformation, along with WC grain breakage and binder extrusion (Fig. 16b). Possible evidence of grain uplifting at the edges of the scratch was also noted. The micro-fracture of WC grains is mainly observed perpendicular to the direction of the sliding direction. It is noticeable from Fig. 16a-d that the width of the grooves increased considerably as the system load increased. Furthermore, the damage rating and the plastic grooves increased when the system load reaches 10-20 N load. Here, we could clearly see the deformation in form of a trough of the WC grains (within the scratched area), also the extrusion of the binder highly takes place at the bottom of the scratches. Fig. 16c inset shows clear evidence of granular cracks from backscattered electron image. In contrast, NbC-cermet shows a significant 
increase in plastic deformation as the load increases (Fig. 16e-h). Addition to that some of the micro cracks are noticeable under high loads (Fig. 16g-h). The effect of micro-cracks (within the grains and between the binder and grain) is strongly pronounced on the scratch edges. However, there is no significant binder removal on the surface of the NbC-cermet as compared to the WC-Co. The secondary electron images (inset) also show that a striped layer of the material has formed on the scratch path as a result of scratch.
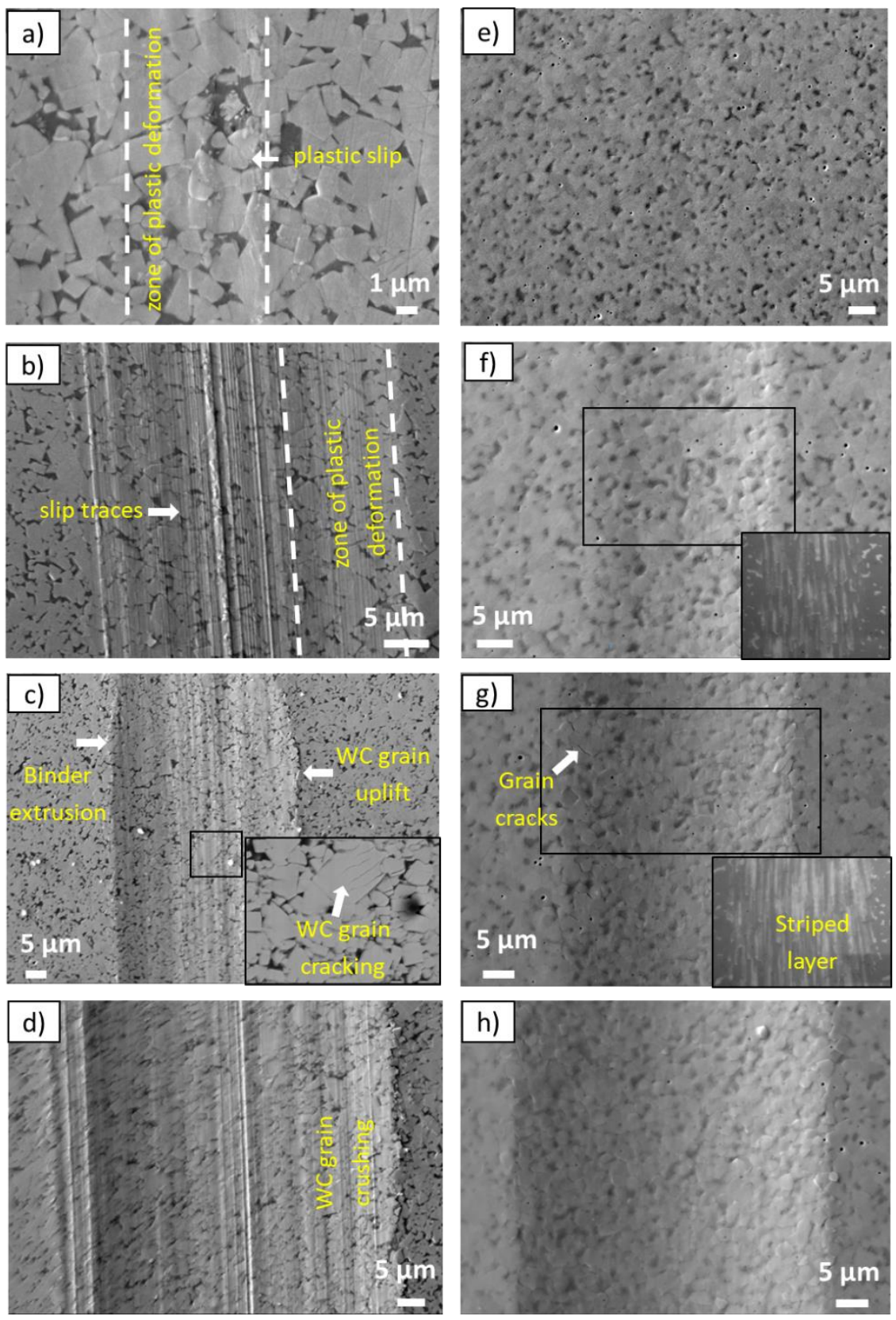

Fig. 16. SEM micrographs of (a-d) WC-Co and (e-h) NbC-cermet at $1 \mathrm{~N}(\mathrm{a}, \mathrm{e}), 5 \mathrm{~N}(\mathrm{~b}, \mathrm{f}), 10 \mathrm{~N}(\mathrm{c}, \mathrm{e})$ and $20 \mathrm{~N}(\mathrm{~d}, \mathrm{~h})$ load

The scratch speed increases from $0.2 \mathrm{~mm} / \mathrm{s}$ (Fig. 16a) to $5 \mathrm{~mm} / \mathrm{s}$ (Fig. 17a), leading to fracture of WC grains against the load and the extensive area of plastic deformation as noticed from parallel trace lines. Additionally, the binder extrusion was experienced highly on the scratch edges as compared to the low load (Fig. 17b). The formation of the debris and edge chipping can be noticed when the system is experienced at high speed. There is no significant variation in the scratch width of the WC-Co when 
the system exposed high speed (Fig. 17b and 16d). However, it can be noticed that the zone of plastic deformation at the edges of the scratch increased as the system load increased. On the other hand, $\mathrm{NbC}$-cermet does not show any significant variation when speed increases, plastic deformation was the more prominent damage mechanism (Fig. 17c-d).
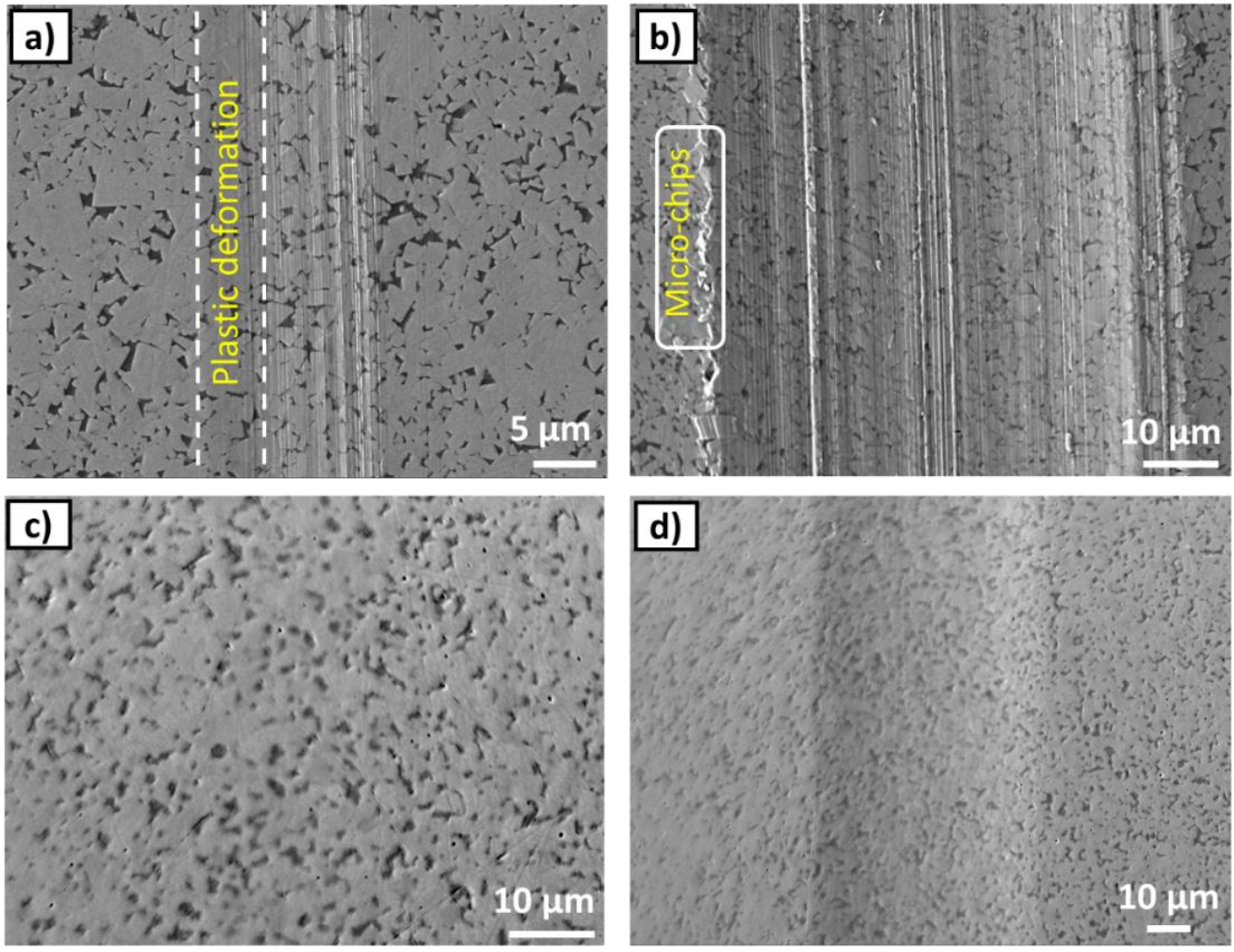

Fig. 17. SEM micrographs of (a-b) WC-Co and (c-d) NbC-cermet with $5 \mathrm{~mm} / \mathrm{s}$ speed at $1 \mathrm{~N}(\mathrm{a}, \mathrm{c}$ ) and $20 \mathrm{~N}(\mathrm{~b}, \mathrm{~d})$ load

Fig. 18a-c confirms that the rate of damage on the surface of WC-Co increases as the radius of the indenter tip decreases. The damage mechanism evolved from superficial plastic deformation to a fracture-dominated mechanism as the tip radius decreased from $100 \mu \mathrm{m}$ to $25 \mu \mathrm{m}$. The surface damage was pronounced at $25 \mu \mathrm{m}$ penetration (Fig. 18c and f), here the mechanically mixed layer takes place as a result of WC grain distortion. It can also be noted that the amount of binder extrusion was more as the tip radius of the indenter became smaller. As similar to WC-Co, the surface defect of $\mathrm{NbC}$-cermet increases when the tip size of the indenter decreases (Fig. 18d-f). There is a relatively large area of binder phase extruded at the edge of scratch. The formation of the surface body layer clearly shows the mixture of NbC-crushed grains along with the Ni binder phase (Fig. 18f). Some evidence of delamination occurred on the scratched region but the number of surface cracks is seen far away from the scratched area at a smaller tip radius. 

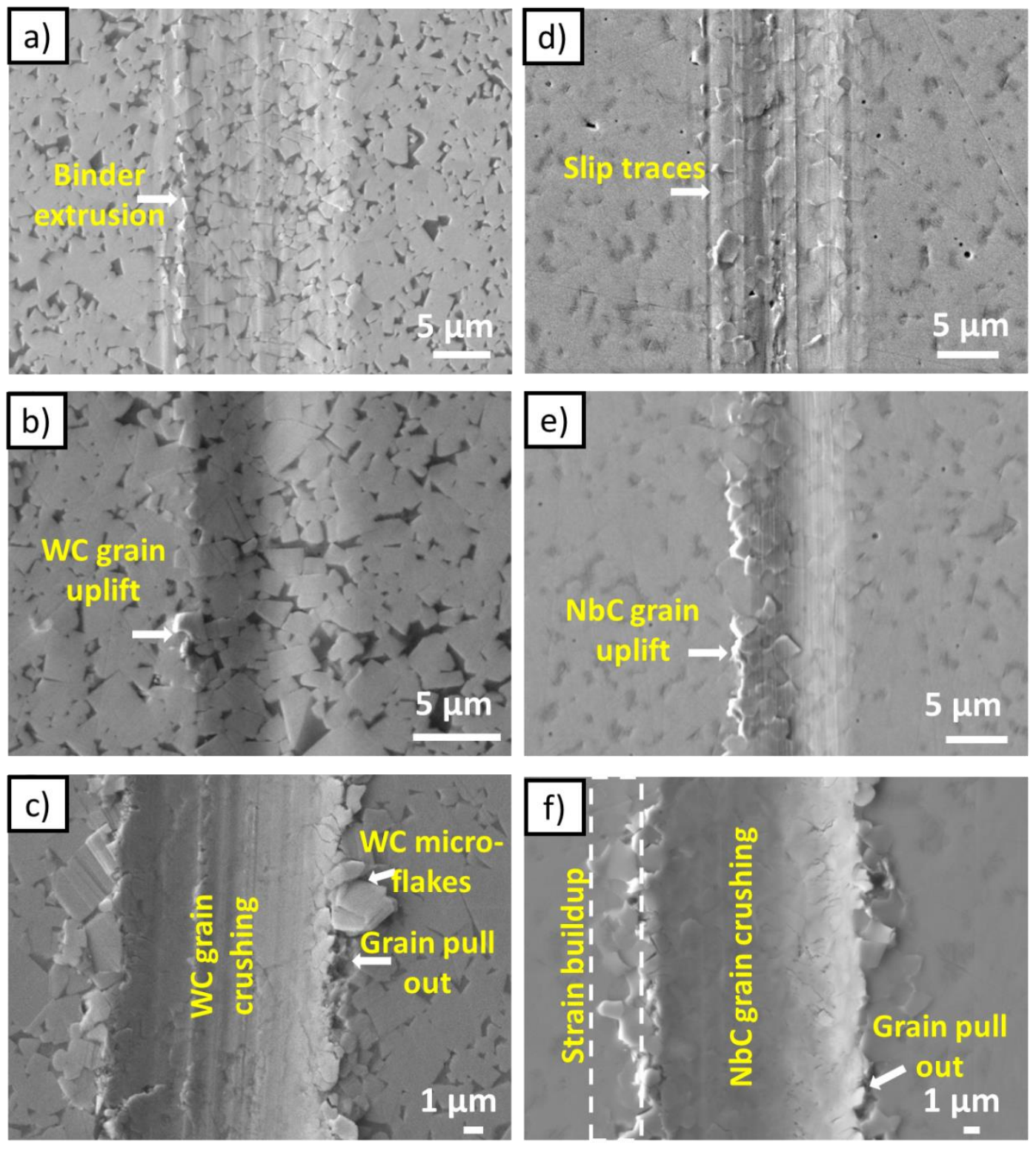

Fig. 18. SEM micrographs of (a-c) WC-Co and (d-f) NbC-cermet for $100 \mu \mathrm{m}$ (a and d), $50 \mu \mathrm{m}$ (b and e), $25 \mu \mathrm{m}$ (c and f) indenter

\subsubsection{Multi-pass scratch testing}

Repeated passes result in grain pull-out, WC grain crushing and associated debris generations (Fig. 19). The width of the groove increased significantly as the system underwent multiple passes. The fracture was a highly pronounced damage mechanism. At 10 passes, there is evidence of carbide fracture and fragmentation of the scratched surface was observed. After 50 passes, the boundaries between the WC grain phase and the binder phase are not as clear as the outer area. Fig. 19c. shows the surface of a WC-Co after 100 pass, the scratched surface appears to be a built-up of a thin surface smeared layer (Fig. 19c). The backscattered electron image (inset) shows the built-up layer which contains some larger fragments and more fine-grained fragments of WC. At $5 \mathrm{~N}$ load, the presence of scratches that completely alters the normal structure was noticed (Fig. 19d). As the number of passes increased, there was clearly crumbling or extrusion of the binder at both ends. However, the build-up of a surface layer on the WC-Co surface remains the same for both 50 and 100 passes (Fig. 19e\&f). Evidence of embedding fragmented WC beads on the binder layer producing a surface layer on the top surface due 
to repeated contact is prematurely visible after 10 passes at $20 \mathrm{~N}$ load (Fig. 19g-i). However, there is evidence of delamination on the surface layer from the resulting surface (Fig. 19h-i).
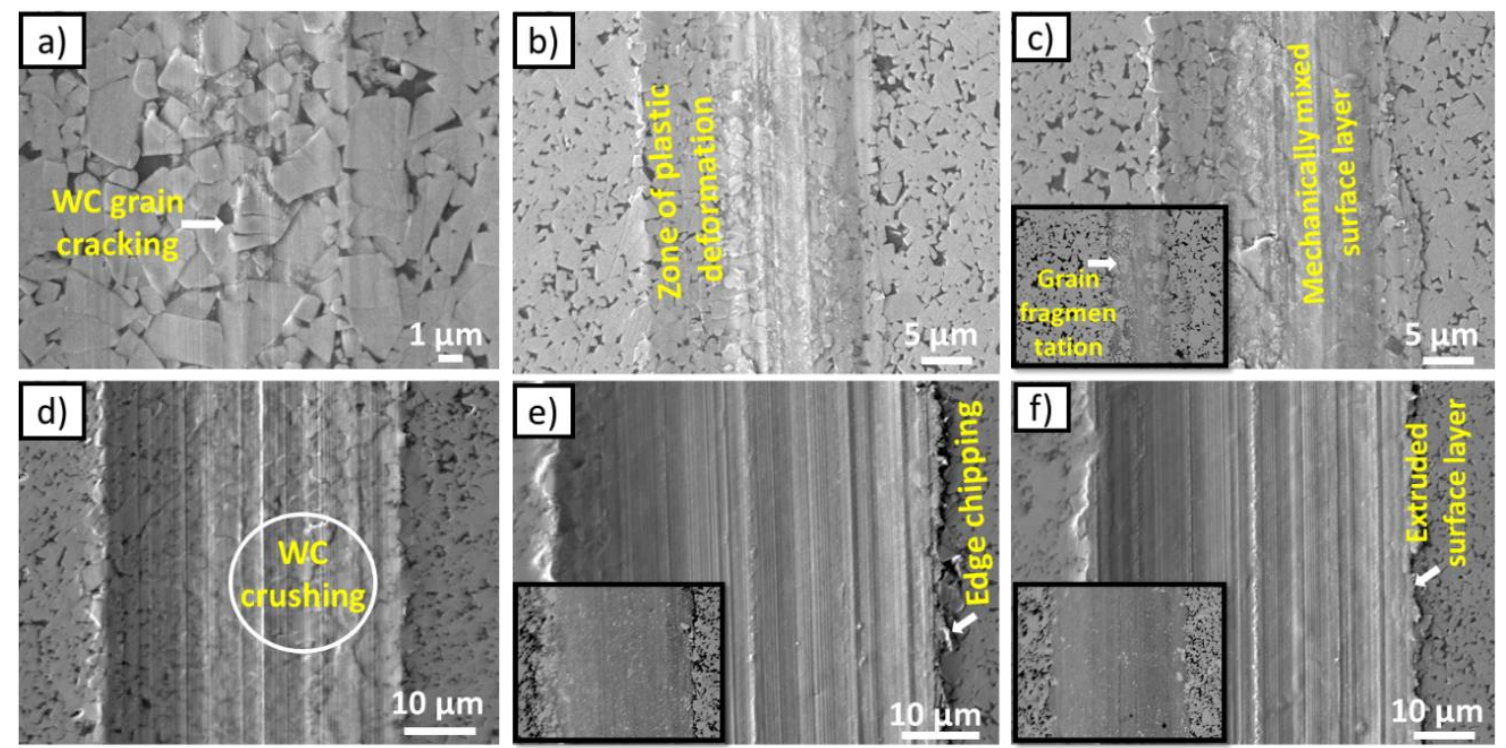

3

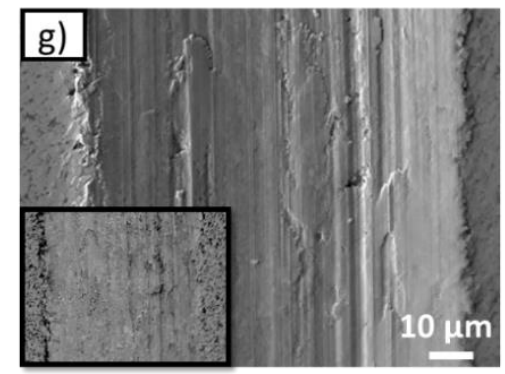

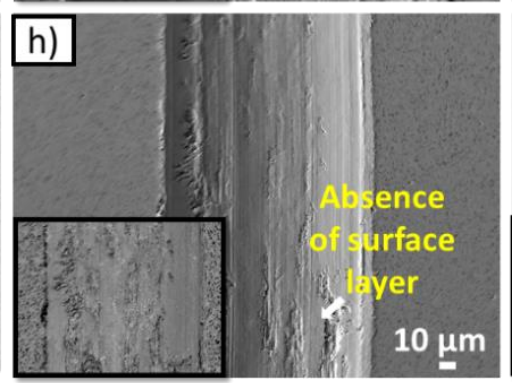

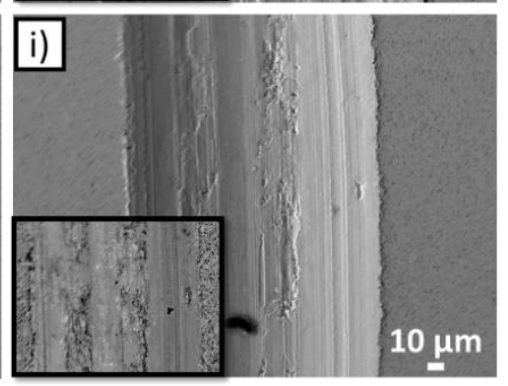

Fig. 19. Worn surface micrographs of WC-Co with respect to (a-c) $1 \mathrm{~N},(\mathrm{~d}-\mathrm{f}) 5 \mathrm{~N}$ and (g-i) $20 \mathrm{~N}$ load after 10 passes $(a, d$ and $g), 50$ passes (b, e and $h$ ) and 100 passes (c, $f$ and $i)$. The insets are at the same magnification.

On the contrary, NbC-cermet surfaces performed well against $200 \mu \mathrm{m}$ indenter than that of the WCCo (Fig. 20a-f). The surface showed many slip line traces with surface distortion when the number of passes increased, indicating the surface plastic deformation. However, the $20 \mathrm{~N}$ load shows a lot of $\mathrm{NbC}$ grain uplifts at the edge of the scratch during 10 pass sliding. In addition, grain pullout accompanied by plastic grooving was noted in several places during repeated passes. The first isolated cavities of significant fracture damage occur only after 10 passes for $20 \mathrm{~N}$ load (Fig. 20g-i). After 50 passes, the surface shows many individual $\mathrm{NbC}$ grain fragments along with binder extrusion (Fig. 20h). It is also noteworthy to mention that the amount of binder extrusion was low in the case of $\mathrm{NbC}$ cermet as compared to WC-Co. The granular cracks such as intergranular and transgranular are also visible on the scratched area when the system is exposed to a high load. The intergranular cracks are formed at the scratch edges, where the transgranular cracks are visible in the center of the scratch. 

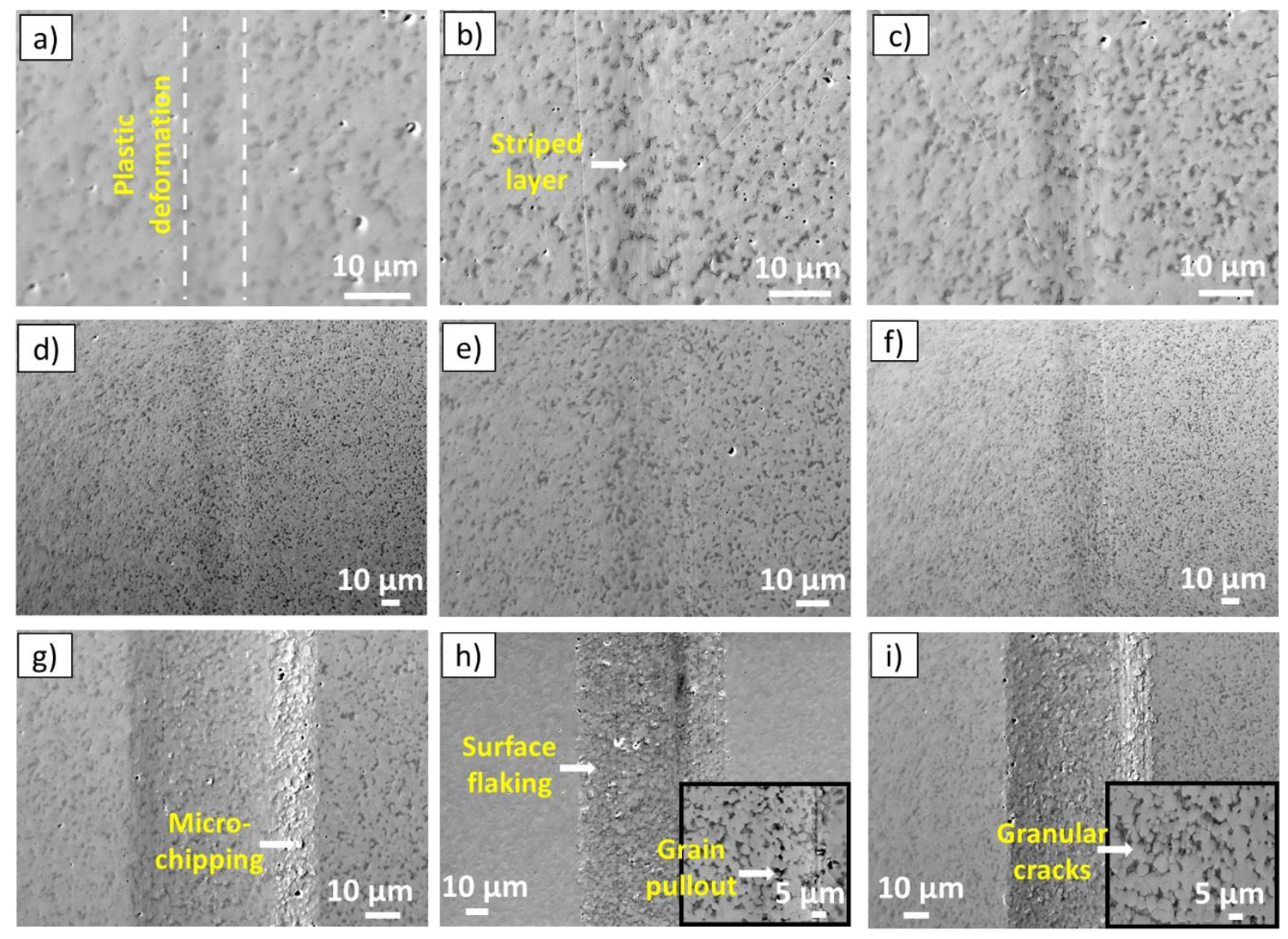

Fig. 20. Worn surface micrographs of NbC-cermet with respect to (a-c) $1 \mathrm{~N},(\mathrm{~d}-\mathrm{f}) 5 \mathrm{~N}$ and (g-i) $20 \mathrm{~N}$ load after 10 passes ( $a, d$ and $g), 50$ passes (b, $e$ and $h$ ) and 100 passes (c, $f$ and $i)$.

\subsubsection{Degree of superimposition}

Fig. 21 shows the superimposition of scratches obtained from WC-Co with a normal load of $1 \mathrm{~N}(\mathrm{a}-\mathrm{c})$ and $20 \mathrm{~N}$ (d-f). During low load (1 N), increasing the DoS from $-100 \%$ to $90 \%$ shows no significant variations on the surfaces. There were some signs of grain fracture on the surfaces, but the resulting wear mechanism is mainly plastic deformation. When the surface was subjected to a high load, binder extrusion and grain fractures accompanied by severe plastic deformation were observed (Fig. 21d-e). A high degree of superimposition resulting in a high material loss due to binder extrusion, excessive carbide cracking, and fragmentation of WC grains. The DoS at $90 \%$, shows two different surface patterns on the scratched region; (1) complete removal of the binder phase which contains unsupported carbide grains, (2) a new surface layer formed on top of the scratch surface by reembedding WC-broken grains on the binder surface (Fig. 21f). Likewise, NbC-cermet exhibits the plastic deformation dominated wear mode under low load $(1 \mathrm{~N})$, see Fig. 22a-c. However, the mechanism turned into fracture-dominated failure when the surface is subjected to high load, this is where the material removal takes place (Fig. 22d-f). The inset shows the high voltage electron backscattered image which clearly explains the fracture of NbC-grains. Fig. 23 shows the scratch depth effect of scratches under low $(1 \mathrm{~N})$ and high load $(20 \mathrm{~N})$. The depth of the grooves decreased until the DoS reaches $50 \%$, then the depth increased considerably. In comparison, the NbC-cermet shows a very low scratch depth at low load, but at higher load and increasing degree of superimposition lead to higher material removal $(x 1.7)$ than the WC-Co. 

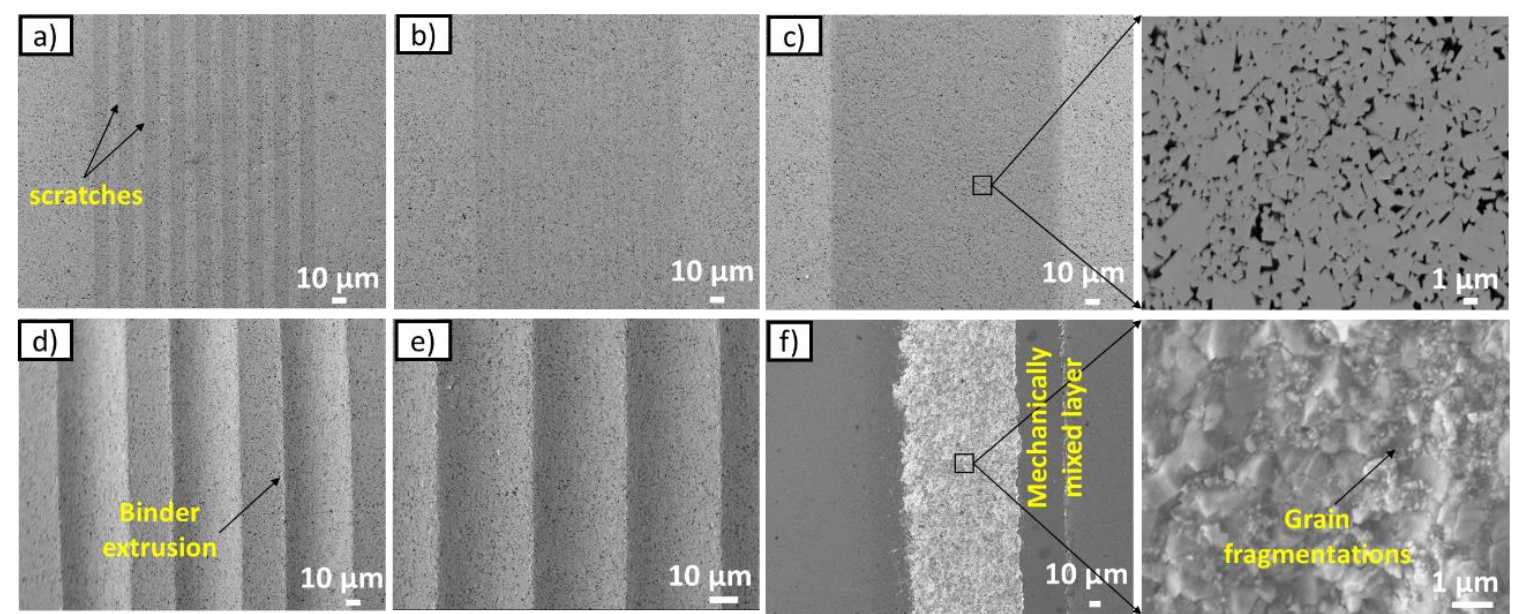

2 3
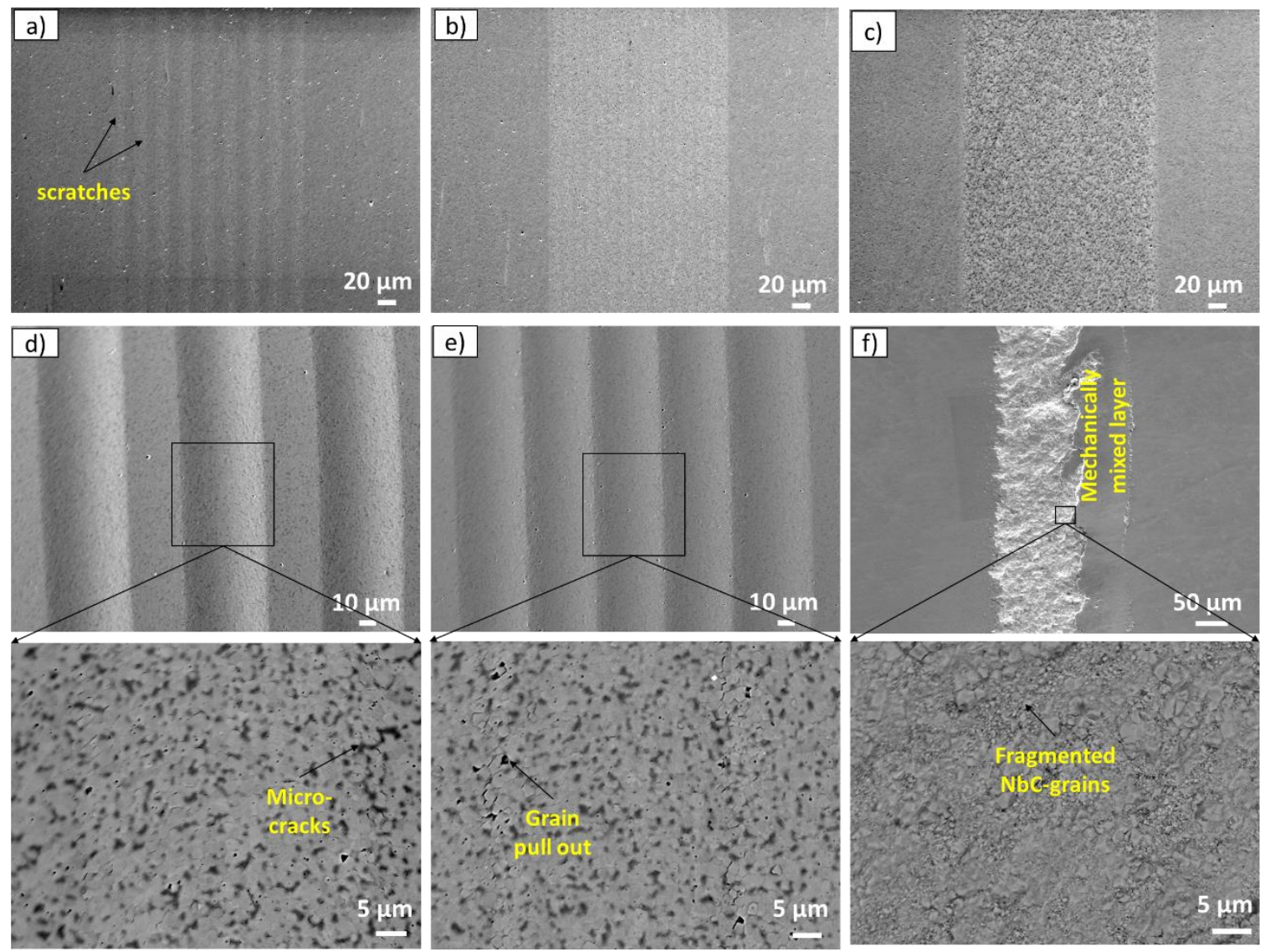

Fig. 22. Superimposition of scratches for NbC-cermet at (a-c) $1 \mathrm{~N}$ and (d-f) $20 \mathrm{~N}$ load with DoS $=-$ $100 \%(a$ and $d)$, DoS $=0 \%(b$ and $e$ ) and DoS $=90 \%$ (c and $f$ ) 


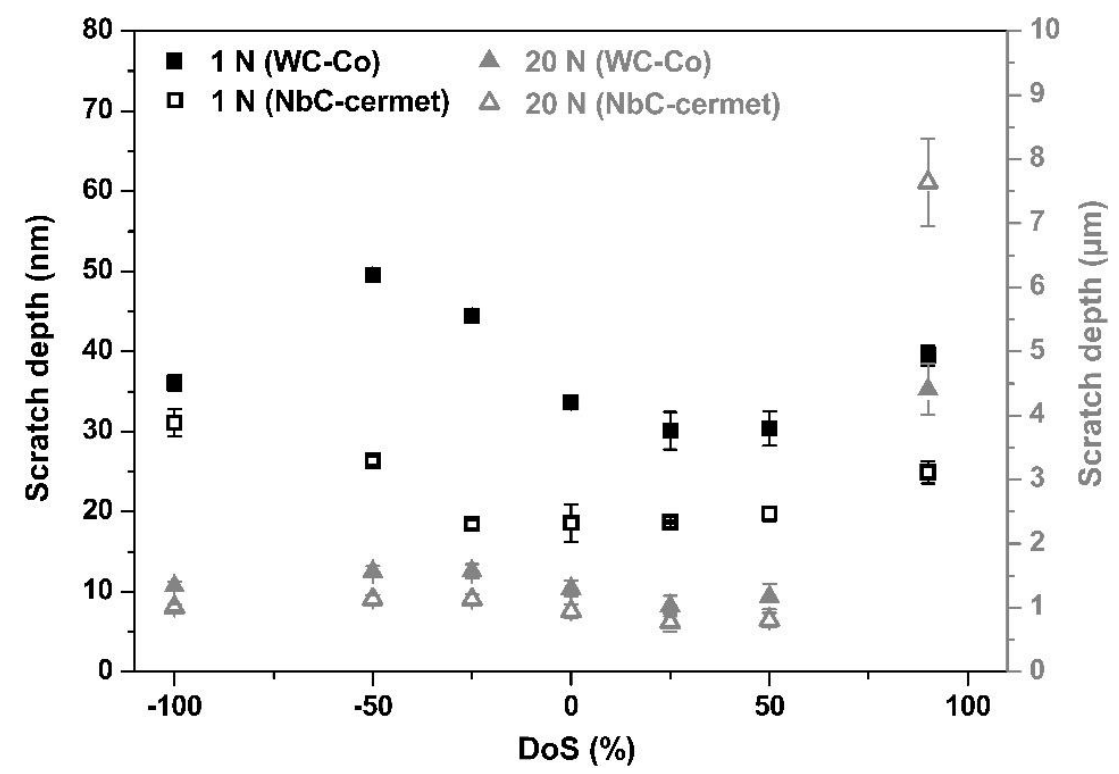

Fig. 23. Effect of DoS on the scratch depth

Superimposition of indentation does not show a substantial material loss on both WC-Co and NbCcermet surface. However, the effect creates plastic stress build-up and significant fracture on the material surfaces. At low load $(1 \mathrm{~N})$ the indentation marks are not clearly visible, which further confirms no surface deviations but this can be noticeable at a higher load (Fig. 24). Both surfaces performed well when the superimposition takes place, while the NbC-cermet (Fig. 24b) on the other hand shows considerable surface cracks that are not visible in WC-Co (Fig. 24a). The effect of carbide breakage due to cracks on the NbC-cermet increased as the DoS increased. Evidence of cracks was well observed near the edge of the notch. Furthermore, there is no clear trend in the penetration depth at a load of $1 \mathrm{~N}$, but the superimposition effect relatively increases the depth of the penetration when the system load increased to $20 \mathrm{~N}$ (Fig. 25).
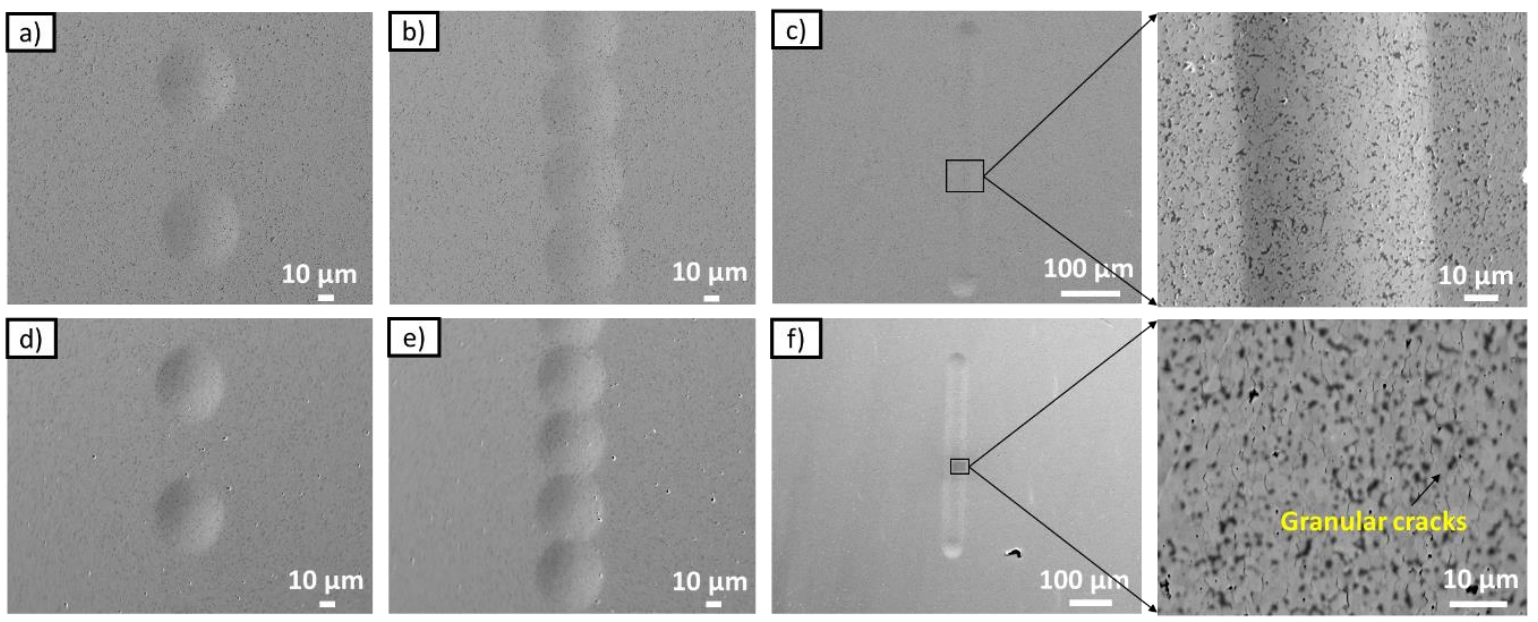

Fig. 24. Superimposition of indentations for (a-c) WC-Co and (d-f) NbC-cermet at $20 \mathrm{~N}$ load with DoS $=-100 \%(a$ and $d)$, DoS $=0 \%(b$ and $e)$ and DoS $=90 \%$ ( $c$ and $f$ ) 


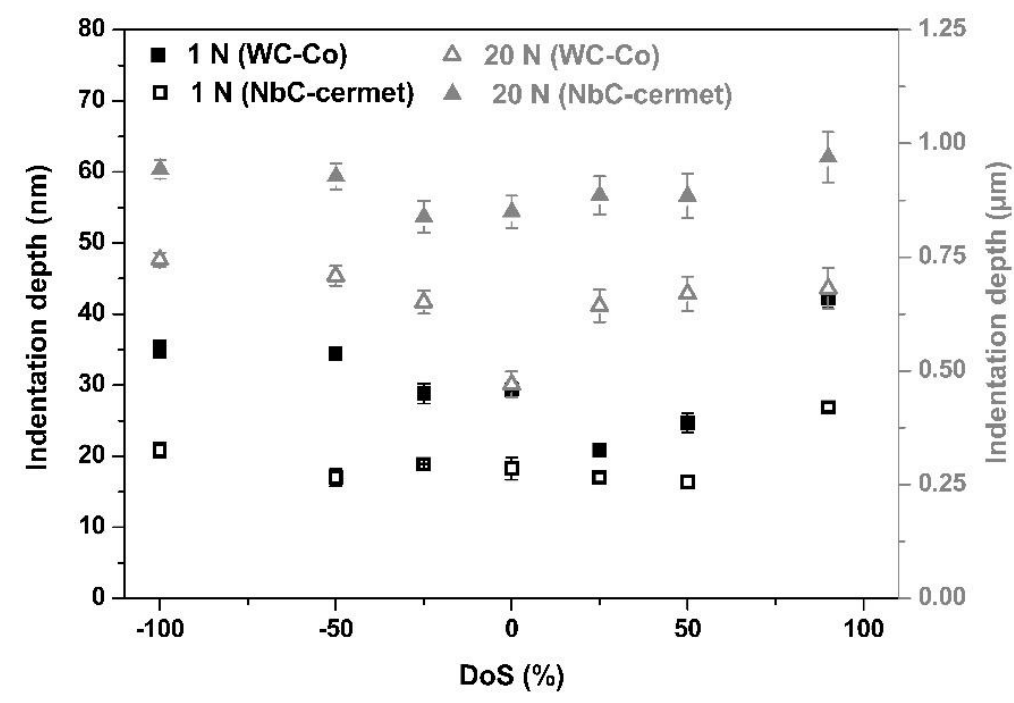

Fig. 25. Effect of DoS on the indentation depth

\subsection{Surface oxidation}

The energy-dispersive X-ray spectroscopy (EDS) results confirm that the surface underwent oxidation as the number of passes increased, as shown in Fig. 26. A considerable amount of oxygen that clearly visible on the scratch surface of the WC-Co (Fig. 26a\&b) and NbC-cermet (Fig. 26c\&d) when the repeats changing from a single pass to 100 passes. The wear debris particles are formed as oxides of $\mathrm{W}\left(\mathrm{WO}_{3}\right)$, $\mathrm{Nb}\left(\mathrm{Nb}_{2} \mathrm{O}_{5}\right), \mathrm{Co}\left(\mathrm{CoO}, \mathrm{CO}_{3} \mathrm{O}_{4}\right)$ and $\mathrm{Ni}\left(\mathrm{NiO}, \mathrm{Ni}_{2} \mathrm{O}_{3}\right)$. The intensity of the theses oxides are strong as the number of passes increases. There are some additional possibilities in the formation of cobalt oxide $\left(\mathrm{CoO}, \mathrm{CoCO}_{2} \mathrm{O}_{4}\right)$ and tungsten cobalt oxide $\left(\mathrm{WCoO}_{4}\right)$. On the other hand, $\mathrm{NbC}$-cermet exhibited relatively higher extensive coverage of niobium oxides $\left(\mathrm{Nb}_{2} \mathrm{O}_{5}\right)$ in worn surfaces (Fig. 26d). The formation of wear debris during repeated scratching is not completely lost as wear debris, formed as a mechanically mixed layer that further resists the surface against abrasion.
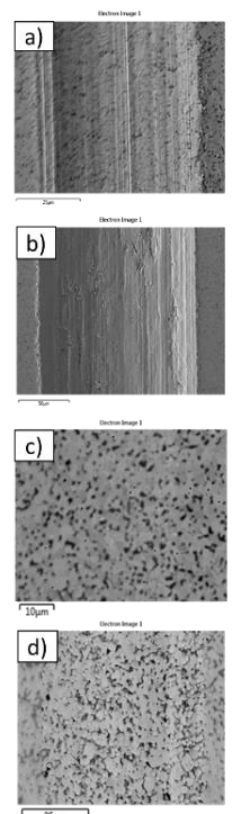
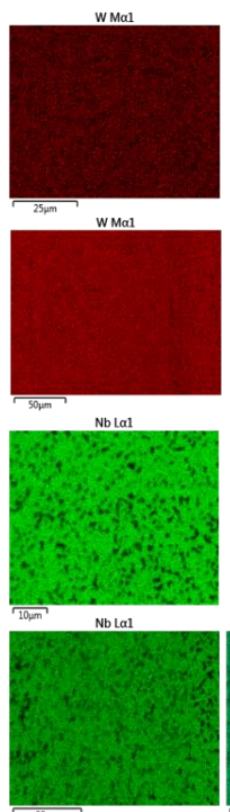
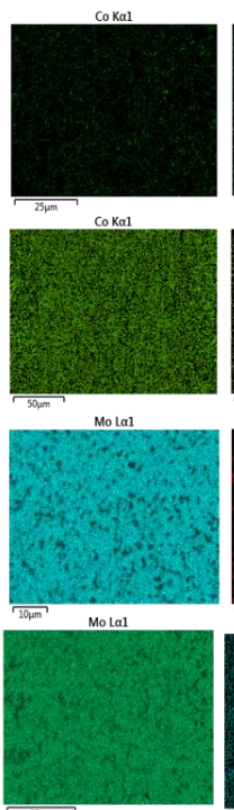
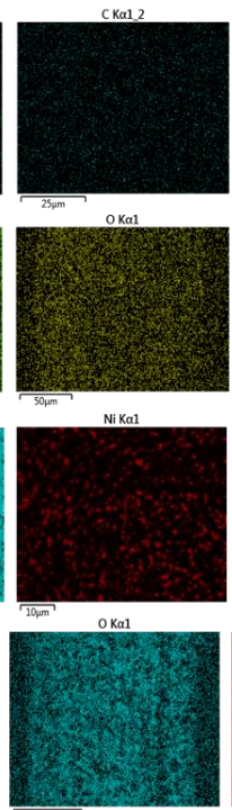
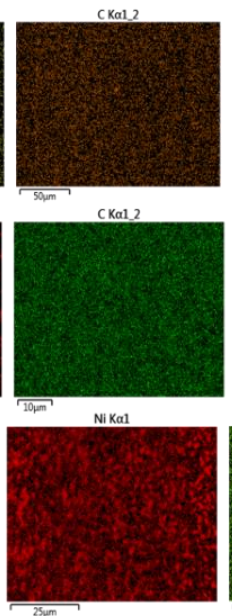

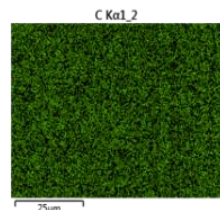

Fig. 26. Worn surface elemental mapping results of (a-b) WC-Co and (c-d) NbC-cermet after single pass ( $a$ and $c$ ) and 100 passes ( $b$ and $d$ ) 


\section{Discussion}

\subsection{Friction trends}

The friction due to deformation can be identified with the force that is used to generate scratch [12]. During a single pass, the load effect shows an upward trend in the coefficient of friction between 1-5 $\mathrm{N}$. It is obvious that the strain rate will be higher, the obtained mechanism will mainly be plastic deformation. The trend becomes gradual after $5 \mathrm{~N}$, the contribution of plastic deformation changing to fracture as confirmed by SEM observation $[12,30]$. The speed effect shows a reduction in the friction results, but the wear mechanism remains the same. Increasing the sliding speed leads to an increase in the surface flash temperature due to the coverage of oxide wear debris [31]. It has been previously reported that the beneficial effect of tungsten oxide $\left(\mathrm{WO}_{3}\right)$ in reducing the coefficient of friction on the WC-Co surface [31]. The size effect of the indenter provides clear increment in the friction results. This is due to the relatively high contact pressure generated by the smaller tip radius, resulting in a high penetration depth that leads to the high surface resistance to sliding [32]. Further investigation of the mean friction coefficient with repeated scratches showed non-linear behaviour, with a decrease for NbC-cermet and an increase for WC-Co. However, the changes are noted after 10 passes where the gradual increase or decrease occurs. This is mainly due to the accumulation of a surface layer on the binder surface during repeated passes leads to stabilizing or lowering the friction coefficient [30]. EDS survey confirms that the accumulated surface layer formed as an oxide film (amorphous/polycrystalline/epitaxial) on the worn surface due to frictional heating (Fig. 26). This probably acts as a solid lubricant between abrasive contacts, which certainly lowers/stabilizes the friction coefficient [33]. During repeated passes, NbC-cermet showed a lower friction coefficient than the WC-Co. This is due to the extended coverage of niobium oxides $\left(\mathrm{Nb}_{2} \mathrm{O}_{5}\right)$ in the worn surface was relatively higher, which could be the reason for reduced friction [26]. The probable reason behind the variation in friction results is still unclear and more work will be needed to fully understand.

\subsection{Wear and damage mechanisms}

In a similar way to the friction, scratch wear in terms of volume loss turned out to be a non-linear trend depends on the observed damage mechanism [30]. The damage can also be caused by a change in the size of the abrasive particle (tip radius in this case) [34]. Considering the geometry of the indenter, the trend in scratch width shows relatively larger in case of $25 \mu \mathrm{m}$ indenter than the $50 \mu \mathrm{m}$ and $100 \mu \mathrm{m}$ indenters (Fig. 11C). This is of course independent to the general relation, where the width of the scratch is directly proportional to the size of the abrasive particle [12]. It is again confirmed that the amount of material removal is highly related to the wear micro-mechanisms and is also interdependent. In multi-pass experiments, the scratch results show a non-linear trend although the applied load is constant. There are two possible validations; (1) the contact area for each pass increases as the number of repeats increases this certainly reduces the stress acting on the surface, (2) the formation of an altered surface layer during repeated passes has a better capacity to further withstand the surface damage compared to the original surface $[13,30]$. The formation of the surface layer mainly occurs due to the process of plastic deformation such as work hardening and the mechanical compaction of crushed carbide grains on the surface [12]. It is also observed that the progressive increase in the volume loss of the scratch for WC-Co is larger as compared to the NbC-cermet. This is due to the $\mathrm{NbC}$ interconnects in the $\mathrm{Ni}$ matrix creates more resistance against plastic grooving as compared to the WC-Co. The effect is further confirmed with the worn surface SEM results, where the evidence of plastic traces shows the effect of plastic deformation but the amount of binder extrusion is considerably low. However, the increasing load initiates the micro-cracks more like a partial Hertz crack of NbC-cermet which further leads to the material removal [12, 35]. Furthermore, the damage 


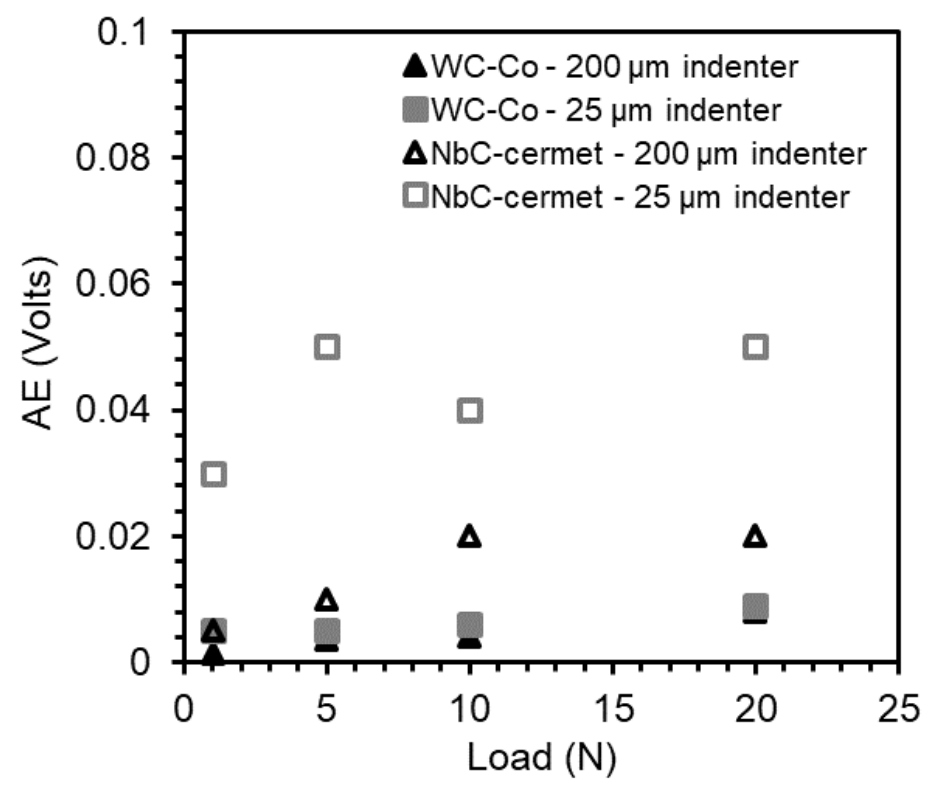

Fig. 27. Load vs. acoustic emission results of WC-Co and NbC-cermet

The degree of superimposition shows the sliding effect of the close surface scratches causes different damage mechanisms. This is due to the build-up of stress on the scratched area, generating extrusion of binder that is further removed or taken away by the scratches that have passed in the same or close location. The effect reflects the scratch depth results where it increases when the degree of superimposition is achieved. The effect was less pronounced with NbC-cermet than with WC-Co. Under high loading, the sample surface initially experienced a significant amount of unsupported grains due to the effect of severe plastic deformation and surface binder extrusion. These unsupported grains further undergo several scratches at the same locations and provide multiple fragments and a surface layer with a mixture of binder and fragments $[12,36]$. Contrary to the low load $(1 \mathrm{~N})$, the NbC-cermet offers increased scratch depth than the WC-Co (Fig. 23). These results imply that the initial scratch resistance for NbC-cermet is relatively better than the WC-Co. However, WC-Co offers a high abrasion resistance than the $\mathrm{NbC}$-cermet during closed body sliding contact. Experiments were done with rolling particles using multiple indentation techniques, with both surfaces experiencing a plastic deformation mechanism. However, the NbC-cermet exhibits a significant fracture-dominated mechanism whereby the cracks develop between the binder and the carbide phase. This can occur more at the edge of the indentation marks. The degree of surface breakage increases when superimposition takes place. This may likely be due to the initial deformation during the first depression, which reduces the mechanical support between the binder and the carbides. If the indentation continues without mechanical support, it further leads to the formation of a shear tongue, resulting in the fracture [37, 38]. Nevertheless, the mechanisms of indentation fracture were not fully understood, more work would be needed to understand the damage assessments. There is no further evidence of material removal during indentation for either hard material. However, the increased degree of superimposition creates a partial Hertzian ring crack on the NbC-surfaces [12]. The depth of indentation and extrusion of the binders at the edges increased when the superimpositions are very close. It is important to note that, the present model helps to analyze the damage mechanism when particles are in rolling contact using superimposed indentations. However, increasing the applied load for different indenter sizes with a relatively large number of indentations would likely help to produce a material removal mechanism. 


\section{Conclusions}

The current methodology for simulating the movement of abrasive particles using a well-controlled single point scratch tester has provided valuable information on the effect of abrasive particle engagement on the multiphase materials. Additional, key findings of the test methodology are listed below:

- At loads between 1-5 N, the friction coefficient shows a significant increase but after $5 \mathrm{~N}$ the trend becomes gradual. This is due to the changes in the wear micro-mechanism from plastic deformation to fracture. The speed effect shows a decreasing trend in the friction coefficient, but the wear micro-mechanism remains the same.

- In a single pass scratch test, the surface damage is primarily initiated by the normal load. The effect of the tip radius (particle size) of the indenter shows considerable variation in the mechanism of damage.

- The effect of attack angle is mainly ignored because of the deviation in the size of the indenter, but a minor deviation $(<5 \mu \mathrm{m})$ in the size $(25 \mu \mathrm{m})$ shows a significant variation in the wear response as well as the wear micro-mechanism.

- During multi-pass scratch, it was found that for both WC-Co and NbC-cermet there was a progressive increase in the coefficient of friction and the scratch volume, but the increase gradually stabilized or decreased as the number of scratch passes increased.

- The process of damage mechanism starts with the build-up of plastic deformation of the carbides, which then leads to fracture and fragmentation of carbides and ends with the formation of a mechanically mixed layer on the surface as a result of WC or NbC fragments reembedding in the binder phase. This also depends on the applied load and number passes of the scratch.

- Superimposition of scratches show the effect of close surface scratches, finding that the severity of damage increases as the degree of superimposition increases.

- Particle rolling was simulated by multiple indentation techniques, where there is no substantial material removal for the scratch length of $400 \mu \mathrm{m}$, although the damage mechanism was mainly subject to fracture in case of NbC-cermet.

- Evidence of surface oxidation was examined when the scratch repeats increased. This is due to the formation of an oxide layer of $\mathrm{W}, \mathrm{Co}, \mathrm{Nb}$ and $\mathrm{Ni}$ wear debris particles that act as a solid lubricant during sliding, further reducing friction and wear.

- An extensive comparative study confirms that the NbC-cermet performs well for the $200 \mu \mathrm{m}$ indenter, but the performance became equal and even diminished as the size of the indenter decreased and the degree of superimposition increased. This reflected the dominance of fracture damage for typical ceramics. Further research on different load, speed and tip radius is required for $\mathrm{NbC}$-cermet to understand the complete damage mechanism.

\section{Acknowledgment}

(1) The authors gratefully acknowledge the funding for Scientific Research Flanders (FWO, Flanders) in the context of the project. G.0772.16N.

(2) To our professor and colleagues at the Soete Laboratory: dr.ir. Dieter Fauconnier, dr. Ir. Wouter Ost, dr. ir. Kannaki Shanmugham Pondicherry, ir. Jonathan Vancoillie, ir. Dhanraj Rajaraman, ir. Gopalakrishnan Ravi for providing the technical support. 


\section{References}

[1] D. Jianxin, Z. Hui, W. Ze, L. Yunsong, Z.J.I.J.o.R.M. Jun, H. Materials, Friction and wear behaviors of WC/Co cemented carbide tool materials with different WC grain sizes at temperatures up to $600 \mathrm{C}, 31$ (2012) 196-204.

[2] M. Woydt, S. Huang, J. Vleugels, H. Mohrbacher, E. Cannizza, Potentials of niobium carbide (NbC) as cutting tools and for wear protection, International Journal of Refractory Metals and Hard Materials, 72 (2018) 380-387.

[3] V. Verma, B.M.J.C.I. Kumar, Tribological characteristics of conventionally sintered TiCN-WC-Ni/Co cermets against cemented carbide, 43 (2017) 368-375.

[4] V.P. Astakhov, The assessment of cutting tool wear, International Journal of Machine Tools and Manufacture, 44 (2004) 637-647.

[5] P.K. Wright, A. Bagchi, Wear mechanisms that dominate tool-life in machining, Journal of Applied Metalworking, 1 (1981) 15.

[6] W.M. da Silva, J.D.B. de Mello, Using parallel scratches to simulate abrasive wear, Wear, 267 (2009) 1987-1997.

[7] R. Trezona, D. Allsopp, I. Hutchings, Transitions between two-body and three-body abrasive wear: influence of test conditions in the microscale abrasive wear test, Wear, 225 (1999) 205-214.

[8] A.B. Van Groenou, N. Maan, J. Veldkamp, Single-point scratches as a basis for understanding grinding and lapping, The Science of Ceramic Machining and Surface Finishing, Vol. 2, National Bureau of Standards Special Technical Publication No. 562, US Government Printing Office Washington DC, 1979, pp. 43-60.

[9] ASTM, Standard Test Method for Determining the High Stress Abrasion Resistance of Hard Materials, ASTM B611 - 13, ASTM, West Conshohocken, PA, USA, 2013.

[10] ASTM, Standard test method for pin abrasion testing, ASTM G132, ASTM, West conshohocken, PA, 2013.

[11] ASTM, Standard test method for measuring abrasion using the dry sand/rubber wheel apparatus, ASTM G65-91 1991, pp. 231-243.

[12] M.J.W. Gee, Low load multiple scratch tests of ceramics and hard metals, 250 (2001) 264-281.

[13] A.J. Gant, J.W. Nunn, M.G. Gee, D. Gorman, D.D. Gohil, L.P. Orkney, New perspectives in hardmetal abrasion simulation, Wear, 376-377 (2017) 2-14.

[14] S.J. Bull, D.S. Rickerby, A. Matthews, A. Leyland, A.R. Pace, J. Valli, The use of scratch adhesion testing for the determination of interfacial adhesion: The importance of frictional drag, Surface and Coatings Technology, 36 (1988) 503-517.

[15] H. Ronkainen, K. Holmberg, K. Fancey, A. Matthews, B. Matthes, E. Broszeit, COMPARATIVE TRIBOLOGICAL AND ADHESION STUDIES OF SOME TITANIUM-BASED CERAMIC COATINGS, in: B.D. Sartwell, J.N. Zemel, G.E. McGuire, F.N. Bresnock (Eds.) Metallurgical Coatings and Thin Films 1990, Elsevier, 1990, pp. 888-897.

[16] A. Vencl, N. Manić, V. Popovic, M. Mrdak, Possibility of the Abrasive Wear Resistance Determination with Scratch Tester, Tribology Letters, 37 (2010) 591-604.

[17] T. Kayaba, K. Hokkirigawa, K. Kato, Analysis of the abrasive wear mechanism by successive observations of wear processes in a scanning electron microscope, Wear, 110 (1986) 419-430.

[18] K. Adachi, I.M. Hutchings, Wear-mode mapping for the micro-scale abrasion test, Wear, 255 (2003) 23-29.

[19] L. Fang, X. Kong, J. Su, Q. Zhou, Movement patterns of abrasive particles in three-body abrasion, Wear, 162 (1993) 782-789.

[20] M. Buijs, K.K.-v. Houten, Three-body abrasion of brittle materials as studied by lapping, Wear, 166 (1993) 237-245.

[21] T.O. Mulhearn, L.E. Samuels, The abrasion of metals: A model of the process, Wear, 5 (1962) 478 498.

[22] D. Chicot, P. de Baets, M.H. Staia, E.S. Puchi-Cabrera, G. Louis, Y. Perez Delgado, J. Vleugels, Influence of tip defect and indenter shape on the mechanical properties determination by indentation 
of a TiB2-60\%B4C ceramic composite, International Journal of Refractory Metals and Hard Materials, 38 (2013) 102-110.

[23] M.G. Gee, A. Gant, B. Roebuck, K. Mingard, Wear of hardmetals, (2014).

[24] A. Gant, M.J.I.J.o.R.M. Gee, H. Materials, Abrasion of tungsten carbide hardmetals using hard counterfaces, 24 (2006) 189-198.

[25] S. Mezlini, P. Kapsa, C. Henon, J. Guillemenet, Abrasion of aluminium alloy: effect of subsurface hardness and scratch interaction simulation, Wear, 257 (2004) 892-900.

[26] S.G. Huang, J. Vleugels, H. Mohrbacher, M. Woydt, Microstructure and tribological performance of NbC-Ni cermets modified by VC and Mo2C, International Journal of Refractory Metals and Hard Materials, 66 (2017) 188-197.

[27] D.K. Shetty, I.G. Wright, P.N. Mincer, A.H. Clauer, Indentation fracture of WC-Co cermets, Journal of Materials Science, 20 (1985) 1873-1882.

[28] ASTM, standard test method for scratch hardness of materials using a diamond stylus, ASTM G171 2009, pp. 1-7.

[29] J.J.J.o.a.p. Archard, Contact and rubbing of flat surfaces, 24 (1953) 981-988.

[30] J.C.P. Zuñega, M.G. Gee, R.J.K. Wood, J. Walker, Scratch testing of WC/Co hardmetals, Tribology International, 54 (2012) 77-86.

[31] N. Vashishtha, S.G. Sapate, Abrasive wear maps for High Velocity Oxy Fuel (HVOF) sprayed WC12Co and Cr3C2-25NiCr coatings, Tribology International, 114 (2017) 290-305.

[32] Q.J. Wang, D. Zhu, Hertz Theory: Contact of Spherical Surfaces, in: Q.J. Wang, Y.-W. Chung (Eds.) Encyclopedia of Tribology, Springer US, Boston, MA, 2013, pp. 1654-1662.

[33] J.A.R. Wesmann, N. Espallargas, Elucidating the complex role of surface oxides formed during sliding of self-mated warm sprayed WC-CoCr in different environments, Tribology International, 94 (2016) 360-372.

[34] M. Thakare, J. Wharton, R. Wood, C.J.W. Menger, Effect of abrasive particle size and the influence of microstructure on the wear mechanisms in wear-resistant materials, 276 (2012) 16-28.

[35] T.R. Wilshaw, R. Rothwell, Instrumented Scratch Test for measuring the Fracture Behaviour of Strong Solids, Nature Physical Science, 229 (1971) 155-157.

[36] M.G. Gee, L. Nimishakavi, Model single point abrasion experiments on WC/Co hardmetals, International Journal of Refractory Metals and Hard Materials, 29 (2011) 1-9.

[37] S. A. Alidokht, S. Yue, R.R. Chromik, Effect of WC morphology on dry sliding wear behavior of coldsprayed Ni-WC composite coatings, Surface and Coatings Technology, 357 (2019) 849-863.

[38] M. Antonov, I.J.T.I. Hussainova, Cermets surface transformation under erosive and abrasive wear, 43 (2010) 1566-1575. 